\title{
Fludarabine in the treatment of chronic lymphocytic leukemia: a review
}

\author{
Francesca Ricci \\ Alessandra Tedeschi \\ Enrica Morra \\ Marco Montillo
}

Department of Oncology/Haematology, Niguarda Ca'Granda Hospital, Milan, Italy
Correspondence: Marco Montillo Department of Oncology/Haematology, Division of Haematology, Niguarda Ca'Granda Hospital, Piazza Ospedale Maggiore 3, 20162 Milano, Italy

Tel +3902 64444074

Fax +390264442033

Email marco.montillo@ospedaleniguarda.it

\begin{abstract}
Fludarabine (FAMP) is the most effective and most extensively studied purine analog in indolent B-cell malignancies. Its use is indicated for first- and second-line treatment of B-cell chronic lymphocytic leukemia (B-CLL). FAMP as a single agent has produced superior response rates and progression-free survival than standard therapy with chlorambucil and alkylator-based regimen. Efficacy of FAMP may be increased by combining this purine analog with other chemotherapeutic and non-chemotherapeutic agents. FAMP and cyclophosphamide combination (FC) has shown promising results with higher overall response and complete response rates than FAMP in monotherapy, although no difference has been detected in survival. Quality of response and eradication of minimal residual disease (MRD) have been reported to be associated with prolonged survival. Eradication of MRD has been achieved by combining FC with mitoxantrone or monoclonal antibody including alemtuzumab or rituximab or both. FAMP has been widely used in non-myeloablative conditioning regimens, often combined with a variety of other cytotoxic agents, with the aim of inducing enough immunosuppression to allow successful engraftment and to exert some pretransplant anti-tumor activity. The current paper provides an overview of use of FAMP as a single agent or as a cornerstone of different therapeutic strategies for treatment of B-CLL patients.
\end{abstract}

Keywords: fludarabine, chronic lymphocytic leukemia, cyclophosphamide

\section{Introduction}

B-cell chronic lymphocytic leukemia (B-CLL) is the most common hematological malignancy in the western world. For several decades the standard treatment for this disease has been chlorambucil (CHL) or cyclophosphamide (CTX), alone or combined with corticosteroids, but complete remissions have been rare with these agents. Other alkylator-based regimens including CVP (CTX, vincristine, prednisone) or CHOP (CTX, doxorubicin, vincristine, prednisone) have been reported to have a comparable efficacy in terms of response and survival. ${ }^{1}$ Since the late 1980 s the success of cytarabine (ara-C) in the treatment of patients with leukemia and lymphoma has generated interest in other nucleoside analogs. Fludarabine (FAMP), cladribine (2CdA) and pentostatin (DCF) are three chemotherapeutic agents belonging to the family of purine analogs and displaying remarkable activity in malignancies arising from the clonal expansion of lymphocytes, and particularly in B-CLL. These three agents have similar chemical structures and mechanisms of action such as induction of apoptosis. However, they also have significant differences, especially in their interactions with enzymes involved in adenosine and deoxyadenosine metabolism. Different studies suggest that FAMP and 2CdA have similar activity in B-CLL while DCF used alone seems to be less active in this disease.

The most extensively studied of these purine analogs in indolent B-cell malignancies is FAMP. Alone, as well as in combination with DNA-damaging drugs or membrane-targeted antibody, FAMP has a particularly well known efficacy in the treatment of B-CLL. 
The current review brings together knowledge of the pharmacokinetics, mechanisms of action and clinical use of FAMP in B-CLL.

\section{Pharmacokinetics}

FAMP is negatively charged at physiological $\mathrm{pH}$ and is therefore unable to enter cells. Thus, it functions as a prodrug that is converted metabolically by dephosphorylation to the antimetabolite, F-ara-A.

F-ara-A appears to be taken into cells by facilitated transport ${ }^{2}$ where it is rephosphorylated to the monophosphate by deoxycytidine kinase and subsequently to the diphosphate and triphosphate. ${ }^{3-5}$ The triphosphate, F-ara-ATP, is the major intracellular metabolite of FAMP and the only metabolite known to have cytotoxic activity. The relatively low concentrations of fludarabine mono- and diphosphate in cells suggests that the activity of deoxycytidine kinase is rate-limiting for triphosphate formation. ${ }^{6}$ Several in vitro investigations focused on the relationship between the dose rate of FAMP, the F-ara-A concentrations in plasma, and the cellular accumulation of F-ara-ATP.

The standard infusion rate for treatment of B-CLL, 25 or $30 \mathrm{mg} / \mathrm{m}^{2}$ of FAMP infused over $30 \mathrm{~min}$, results in $\mathrm{C}_{\max }$ values for $\mathrm{F}$-ara-A that reach 3 to $5 \mu \mathrm{mol} / \mathrm{L}$ at the end of the infusion. ${ }^{7,8}$

Serial sampling of leukemia cells from patients receiving these standard doses of FAMP has demonstrated that the peak concentrations of F-ara-ATP are achieved 4 hours after start of drug infusion. ${ }^{7-11}$

The peak F-ara-ATP concentration appeared somewhat later in patients who received doses of 100 to $125 \mathrm{mg} / \mathrm{m}^{2}$, suggesting that higher plasma F-ara-A concentrations would support linear accumulation for longer periods. ${ }^{7}$

Although there was heterogeneity among individuals for the rate of F-ara-ATP accumulation, the peak concentrations were clearly proportional to the dose of FAMP infused.

The retention of F-ara-ATP was also variable among individuals. Elimination was generally monophasic, but the half-life in B-CLL cells ranged from a few hours to several days with a median value of 15 hours. ${ }^{11}$ Thus, F-ara-ATP is a relatively long-lived active metabolite, a characteristic that probably accounts for the observed efficacy of daily administration schedules. ${ }^{12,13}$

The constancy of the cellular pharmacokinetics of F-ara-ATP in an individual and the heterogeneity in this parameter among patients suggested the possibility that F-ara-ATP cellular pharmacology might be associated with clinical response to FAMP therapy. No correlation was observed, however, between response and F-ara-ATP peak values, elimination rates and total cellular exposure after the first FAMP injection.

Although FAMP is mostly used as an intravenous (iv) formulation $10 \mathrm{mg}$ FAMP in an immediate release tablet has become available. The bioavailability of oral FAMP is approximately $51 \%-55 \%$ following single and multipledose administration, with low intra-individual variation. ${ }^{14}$ Systemic bioavailability, $\mathrm{C}_{\max }$ and time to $\mathrm{C}_{\max }$ are increased slightly with concomitant food intake; the terminal half-life is unaffected ${ }^{15}$ This, and other pharmacokinetic studies, ${ }^{16,17}$ have shown that a once-daily oral FAMP dose of $40 \mathrm{mg} / \mathrm{m}^{2}$ would provide a similar systemic exposure to fludarabine $25 \mathrm{mg} / \mathrm{m}^{2}$ iv.

Oral FAMP is typically given at a dosage of $40 \mathrm{mg} / \mathrm{m}^{2}$ (7-8 tablets) once daily for 5 days, repeated every 4 weeks for up to 6 cycles.

\section{Mechanism of action}

Every demonstrable cytotoxic mechanism of action of fludarabine requires the presence of F-ara-ATP. The principal action of F-ara-ATP is in the inhibition of DNA synthesis. ${ }^{18,19}$

Several specific enzymes involved with DNA synthesis are targets for inhibition by F-ara-ATP. ${ }^{20}$ In particular, F-ara-ATP competes as an alternative substrate with the normal deoxynucleotide, deoxyadenosine 5'-triphosphate (dATP), inhibiting directly the DNA polymerases. Furthermore F-ara-ATP is able to inhibit DNA primase, an accessory protein that synthesizes an RNA primer required for initiation of lagging strand synthesis by DNA polymerase. ${ }^{21,22}$

F-ara-ATP is also an effective inhibitor of ribonucleotide reductase, resulting in lowering of cellular deoxynucleotide pools which are maintained by this enzyme. ${ }^{23-25}$ This would change the ratio of F-ara-ATP to dATP and consequently self-potentiates the DNA synthesis-directed actions of fludarabine.

In addition, F-ara-AMP is incorporated into DNA, particularly at the 3'-terminus, as purine analog. ${ }^{26,27}$ This results in DNA ligase I inability to join it to an adjacent piece of DNA. Moreover, the free triphosphate interacts with this enzyme to block AMP binding and ligation of single strands.

These actions on DNA ligase I have important implications for the actions of the drug on the function of this enzyme in DNA replication and repair.

Together these actions are likely to result in complete inactivation of DNA synthesis followed by an initiation 
of programmed cell death that ends in apoptosis of the cell. ${ }^{28-30}$

Moreover, F-ara-ATP can induce cell death in quiescent cells in the absence of its incorporation into DNA by the activation of the mitochondrial pathway of the apoptotic cascade. $^{31}$

The mechanism of action of FAMP is reported in Figure 1.

\section{FAMP in monotherapy}

FAMP has been evaluated as monotherapy in several non comparative studies conducted in treated and untreated B-CLL patients and at the time it gives the highest response rate reported for a single agent in B-CLL.

One of the initial studies was conducted by Keating et al. This trial included 68 patients with refractory B-CLL who received FAMP as a single agent at 25 to $30 \mathrm{mg} / \mathrm{m}^{2} / \mathrm{d}$ for 5 days every 4 weeks. Authors described a complete response $(\mathrm{CR})$ rate of $13 \%$ with an overall response (OR) rate of $57 \%$. Median overall survival (OS) was 16 months. Toxicities included thrombocytopenia and neutropenia, with $9 \%$ of patients experiencing major infections. ${ }^{32}$

The largest series of patients reporting FAMP activity in relapsed or refractory B-CLL has been reported by Sorensen et al Seven hundred and three patients were treated with $25 \mathrm{mg} / \mathrm{m}^{2} / \mathrm{d}$ for 5 days every 4 weeks, achieving a complete response (CR) in 3\% of cases with an OR rate of $32 \%$. Median OS was 12.6 months. Major toxicities were hematologic in $43 \%$ of patients, infections in $22 \%$, and neurotoxicity in $14 \% .{ }^{33}$

Small-scale studies have also been conducted in treatment-naïve patients. The initial study, involving 33 patients who were treated with FAMP $\left(30 \mathrm{mg} / \mathrm{m}^{2} / \mathrm{d}\right.$ for 5 days, repeated every 4 weeks), reported an OR rate of $79 \%$, with $33 \%$ of patients achieving a CR and a further 39\% a CR with residual nodules as the only evidence of disease. The response was rapid, usually occurring after 3-6 courses of treatment. ${ }^{34}$

These findings were confirmed by subsequent studies with standard dose of FAMP which reported an OR rates of $80 \%$ to $100 \%{ }^{12,35,36}$ and a median time to disease progression of 33 months. ${ }^{12}$

As previously reported more recently an oral formulation of FAMP has been developed. Oral FAMP is indicated as second-line therapy in patients who have not responded to, or whose disease has progressed during or after treatment with, at least one standard alkylating agent-containing regimen. Recently, in most European countries oral FAMP has been licensed as first-line treatment in B-CLL.

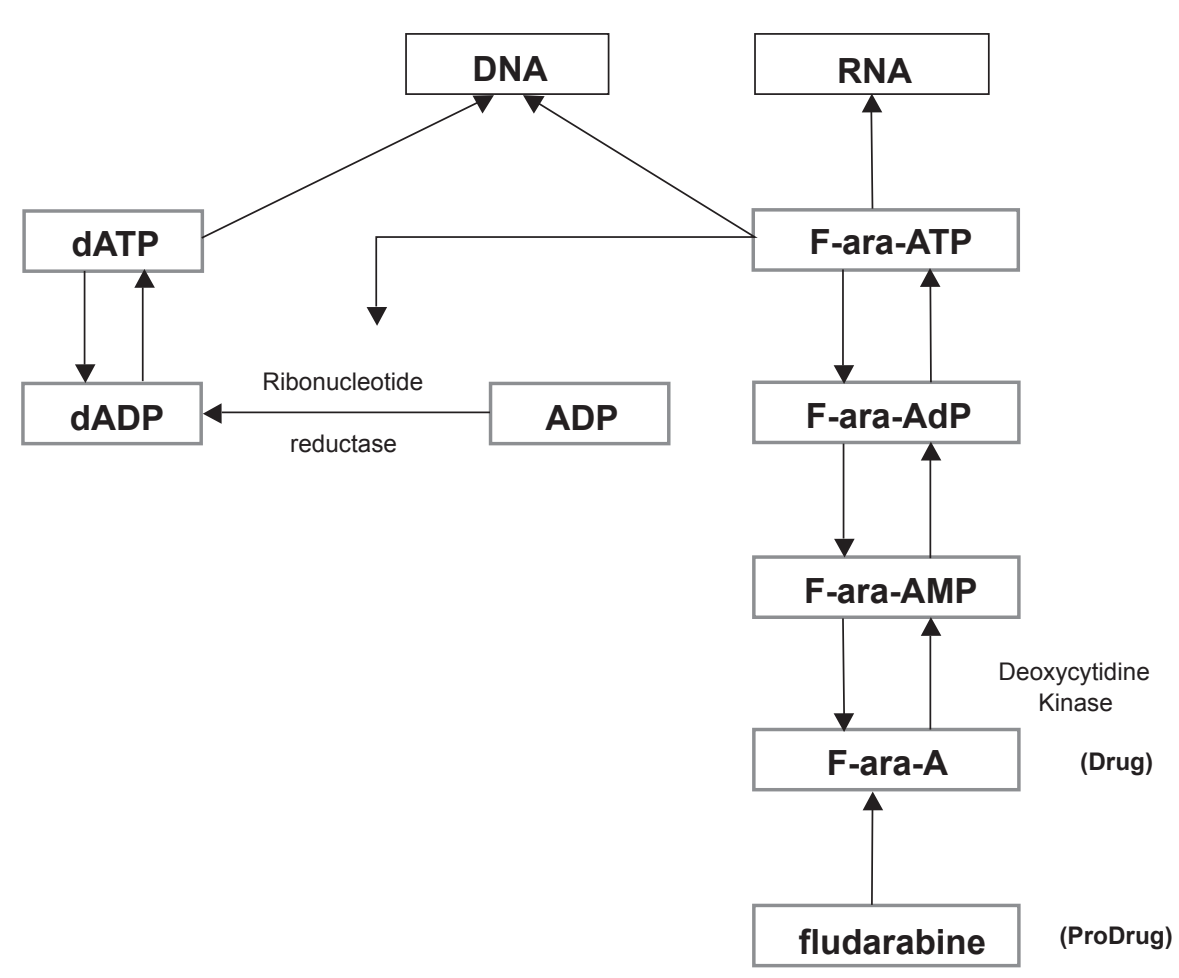

Figure I Metabolism and mechanisms of actions of fludarabine.

Abbreviations: A, adenosine; $\mathrm{dA}$, deoxyadenosine; F-ara-A, 9- $\beta$-D-arabinosyl-2-fluoroadenine; MP,DP,TP refer to nucleoside 5'-monophosphates, diphosphates and triphosphates, respectively. 
In previously treated patients receiving oral FAMP monotherapy OR rates of $46 \%$ to $51 \%$ were achieved, depending on the response criteria used. ${ }^{37}$ Oral FAMP is also an effective first-line treatment. Rossi et al conducted a multicenter open label study in 81 untreated B-CLL patients receiving oral FAMP $40 \mathrm{mg} / \mathrm{m}^{2} / \mathrm{d}$ for 5 days every 4 weeks for 6 to 8 cycles. The OR rate was $71.6 \%$ (CR 37\%) according to International Workshop on Chronic Lymphocytic Leucemia (IWCLL) criteria and 80.2\% (CR 12.3\%) using National Cancer Institute-Working Group (NCI) criteria. The OR was comparable with that achieved in a similar historical cohort who received first-line therapy with iv FAMP. ${ }^{38}$

The next logical step was to compare FAMP with traditional alkylator-based therapies in B-CLL patients. Several phase III studies conducted in the USA and Europe have compared the efficacy of iv FAMP as a single agent against that of CHL, ${ }^{39} \mathrm{CAP}$ (CTX, doxorubicin, prednisone) ${ }^{40,41}$ and CHOP combination ${ }^{41}$ in previously untreated patients with Binet stage $\mathrm{B}$ and $\mathrm{C}$ B-CLL.

The pivotal phase III multicenter study conducted by US Intergroup ${ }^{39}$ compared iv FAMP $\left(25 \mathrm{mg} / \mathrm{m}^{2} / \mathrm{d}\right.$ for 5 days $)$ to oral CHL (40 mg/m²/d for 1 day) and to the combination of the two drugs (iv FAMP $20 \mathrm{mg} / \mathrm{m}^{2} / \mathrm{d}$ for 5 days plus oral CHL ( $20 \mathrm{mg} / \mathrm{m}^{2} / \mathrm{d}$ for 1 day) as first-line therapy. Patients failing initial therapy were allowed to cross over to the other drug.

FAMP-treated patients had significantly higher OR and CR rates than those treated with CHL (63\% vs $37 \%$ and $20 \%$ vs $4 \%$ respectively). The median duration of response and the median progression free survival (PFS) in the FAMP group were significantly longer than in CHL treated patients (25 vs 14 months and 20 vs 14 months respectively). However OS did not differ between the two different treatments. The cross-over planned in this trial may play a role in these results considering that the response rate to $\mathrm{CHL}$ among FAMP failures was very low (7\%) and the response rate to FAMP among CHL failures was significantly higher (46\%). Severe infections and neutropenia were more frequent with FAMP than with CHL. Overall toxic effects were tolerable with the two single-drug regimens, while the combination arm was discontinued during the study because of the toxicity.

FAMP has been compared to CHL plus prednisone in an Italian phase III multicenter study. One hundred fortyseven previously untreated patients with active B-CLL were randomized to receive iv FAMP $\left(25 \mathrm{mg} / \mathrm{m}^{2} / \mathrm{d}\right.$ for 5 days $)$ or oral CHL (30 mg/m² on days 1 and 15) plus intramuscular prednisone (40 $\mathrm{mg} / \mathrm{m}^{2}$ on days $1-5$ and $\left.15-19\right)$. Treatment cycles were repeated every 4 weeks. FAMP was the more effective of the two treatments, resulting in a higher CR rate ( $47 \%$ vs $31 \%$ ), although OR rates were similar in the two arms. The treatment response was more durable with FAMP than with CHL plus prednisone ( 28 vs 21 months). ${ }^{42}$

Recently the German CLL Study Group (GCLLSG) initiated a phase III study (CLL5 protocol) to evaluate the effect of FAMP versus CHL in first line therapy of elderly patients with advanced CLL. Long-term follow-up analysis shows that elderly patients have no significant clinical benefit from first-line therapy with FAMP in comparison to CHL. Though higher CR and OR rate FAMP failed to show any benefit in terms of PFS and OS. A possible explanation for this phenomenon is the longer treatment period with $\mathrm{CHL}$ $(0.4 \mathrm{mg} / \mathrm{kg}$ dose escalation up to $0.8 \mathrm{mg} / \mathrm{kg}$ every 15 day for up to 12 months), that might prevent earlier relapses. Moreover, in cases of relapse FAMP treated patients received either no treatment at all or more intense regimen in comparison to CHL. ${ }^{43}$

A French Cooperative Group phase III study ${ }^{40}$ compared the effectiveness of fludarabine $\left(25 \mathrm{mg} / \mathrm{m}^{2} / \mathrm{d}\right.$ for 5 days) with CAP regimen (CTX $750 \mathrm{mg} / \mathrm{m}^{2}$ iv on day 1 , doxorubicin $50 \mathrm{mg} / \mathrm{m}^{2}$ iv on day 1 , prednisone $40 \mathrm{mg} / \mathrm{m}^{2}$ oral on days 1-5) in first and second-line treatment. A total of 6 cycles at 28 day intervals were administered. Higher response rate to FAMP was observed in both untreated ( $71 \%$ vs $60 \%$ ) and pre-treated ( $48 \%$ vs $27 \%$ ) cases, although the difference was statistically significant only in pre-treated cases. In the latter group, remission duration and survival did not differ between treatment groups. In untreated cases, on the other hand, fludarabine induced significantly longer remissions than CAP.

In a second French Cooperative Group study 938 treatment-naive patients were randomized to receive FAMP, CAP or CHOP (vincristine $1 \mathrm{mg} / \mathrm{m}^{2}$ iv on day 1 , doxorubicin $25 \mathrm{mg} / \mathrm{m}^{2}$ iv on day 1 , CTX $300 \mathrm{mg} / \mathrm{m}^{2}$ oral on days $1-5$, prednisone $40 \mathrm{mg} / \mathrm{m}^{2}$ iv oral on days $1-5$ ) repeated every 4 weeks. The response rate was greater in patients treated with FAMP and CHOP compared to CAP. There was no difference in PFS and OS between the groups. Time of second-line therapy was significantly longer in the FAMP group while the purine analog was better tolerated compared to CHOP and CAP. Consequently patients treated with fludarabine enjoyed a better quality-adjusted time without symptoms or toxicity. ${ }^{41}$

Some investigators attempted to identify factors that predict a good response to FAMP. In an M.D. Anderson Cancer Center study of 264 pre-treated and untreated B-CLL 
patients receiving FAMP and prednisone a multivariate analysis-derived prognostic model for response to treatment was proposed and 4 factors were found to be significantly associated with worse response: Rai III-IV stage disease, prior therapy, older age, and low albumin levels. ${ }^{44}$

Dhöner et al studied mononuclear cells from 100 patients (90 B-CLL, 7 B-cell prolymphocytic leukemia, 3 Waldenström macroglobulinemia) using fluorescence in situ hybridization (FISH) with a genomic p53 DNA probe. Seventeen of the 100 patients exhibited a monoallelic p53 gene deletion by FISH. Fifty patients received therapy with purine analogs. The response to therapy depended strongly on the presence of a p53 gene deletion. None of the 12 patients with a deletion responded to therapy with FAMP or pentostatin, while 20 of 36 patients without a deletion who were assessable for response achieved a remission $(\mathrm{p}<0.001)$. The difference in survival probabilities from the time of diagnosis and from the start of treatment with purine analogs between the two groups was highly significant $(\mathrm{p}<0.001)$. In multivariate analysis, p53 gene deletion was the strongest prognostic factor for survival. In conclusion, p53 gene deletion predicts for non-response to therapy with purine analogs and for poor survival in B-CLL. ${ }^{45}$ More recently, Valgañón et al analyzed the aberrations in p53, including the methylation status of its promoter, in 54 patients with advanced stage B-CLL who received FAMP as first-line. They confirmed that the abnormalities of p53, either methylation or deletion, were associated with short survival and non-response to therapy. ${ }^{46}$

The experiences with FAMP in monotherapy are reported in Table 1.

\section{FAMP in combination treatment}

Efficacy of FAMP may be increased combining this purine analog with other agents. Indeed, FAMP has been shown to have a biochemical modulating effect on other chemotherapeutic agents in vitro, for example CTX, ${ }^{47,48}$ ara-C $\mathrm{C}^{49,50}$ cisplatin ${ }^{51,52}$ and mitoxantrone. ${ }^{53,47}$ In view of this synergistic/ biochemical modulating effect, attempts to improve the CR and relapse rate have been explored with the use of FAMP in combination with other chemotherapeutic agents. Studies exploring efficacy and safety FAMP-based schedule are listed in Tables 2, 3 and 4.

\section{FAMP with alkylating agents}

Taking into account the wide use of CHL in B-CLL the combination of FAMP plus CHL has been explored in clinical trials. ${ }^{54,55}$ This treatment did not show a significant improvement in response rate or survival compared with
FAMP alone. Furthermore, treatment with FAMP plus CHL appeared to be associated with a higher incidence of adverse events compared with either FAMP or CHL alone.

In particular in the CALGB study ${ }^{39}$ as previously mentioned, FAMP treatment was compared to CHL and to the combination of the two drugs as first-line therapy. Assignment of patients to the FAMP plus CHL group was stopped when a planned interim analysis revealed excessive toxicity and a response rate that was not better than the rate with FAMP alone. ${ }^{39,56}$

FAMP and CTX is by far the best investigated FAMP- combination. It has been examined in several trials, including trials with additional filgrastim support and with mitoxantrone added to the regimen.

One of the first non-comparative studies was conducted by O'Brien et al in 128 untreated and pre-treated patients with B-CLL who received FAMP $30 \mathrm{mg} / \mathrm{m}^{2} / \mathrm{d}$ iv for 3 days and CTX at either $500 \mathrm{mg} / \mathrm{m}^{2} / \mathrm{d}$ for 3 days, $350 \mathrm{mg} / \mathrm{m}^{2} / \mathrm{d}$ for 3 days, or $300 \mathrm{mg} / \mathrm{m}^{2} / \mathrm{d}$ for 3 days. The CTX dose was decreased because of myelosuppression in the early part of the study. Patients were stratified into four groups according to pretreatment status, that is untreated, treated with alkylating agents, treated with and responsive to FAMP with or without alkylating agents but relapsing, and treated with and refractory to FAMP with or without alkylating agents.

The OR and the CR rates were $88 \%$ and $35 \%$ respectively for previously untreated patients, compared with $85 \%$ and $15 \%$ in patients previously treated with alkylating agents. In the subgroup of patients refractory to FAMP, an OR rate of $39 \%$ suggests that the combination of FAMP with CTX may be synergistic in this group. The median time to progression was 12 to 38 months in patients who had received prior therapy. In previously untreated patients, the median time to progression and survival duration had not been reached after a median follow-up of 41 months. ${ }^{57}$

Similar results in terms of $\mathrm{OR}$ and $\mathrm{CR}$ rates were reported in a smaller study conducted in treatment-naïve patients by Flinn et al. In this study combination of FAMP and CTX were investigated with the filgrastim support FAMP $20 \mathrm{mg} / \mathrm{m}^{2} / \mathrm{d}$ iv for 5 days and CTX $600 \mathrm{mg} / \mathrm{m}^{2} / \mathrm{d}$ iv on day 1 were followed by filgrastim $5 \mu \mathrm{g} / \mathrm{kg}$ for 10-14 days starting around day 8 . Treatment was repeated every 28 days for a maximum of six cycles. An interesting finding was the reduced incidence of leukocytopenia, and the increased incidence of thrombocytopenia and anemia in patients receiving G-CSF in addition to the FAMP plus CTX combination. ${ }^{58}$

FAMP associated to CTX has also been investigated in 3 recently published comparative studies. 


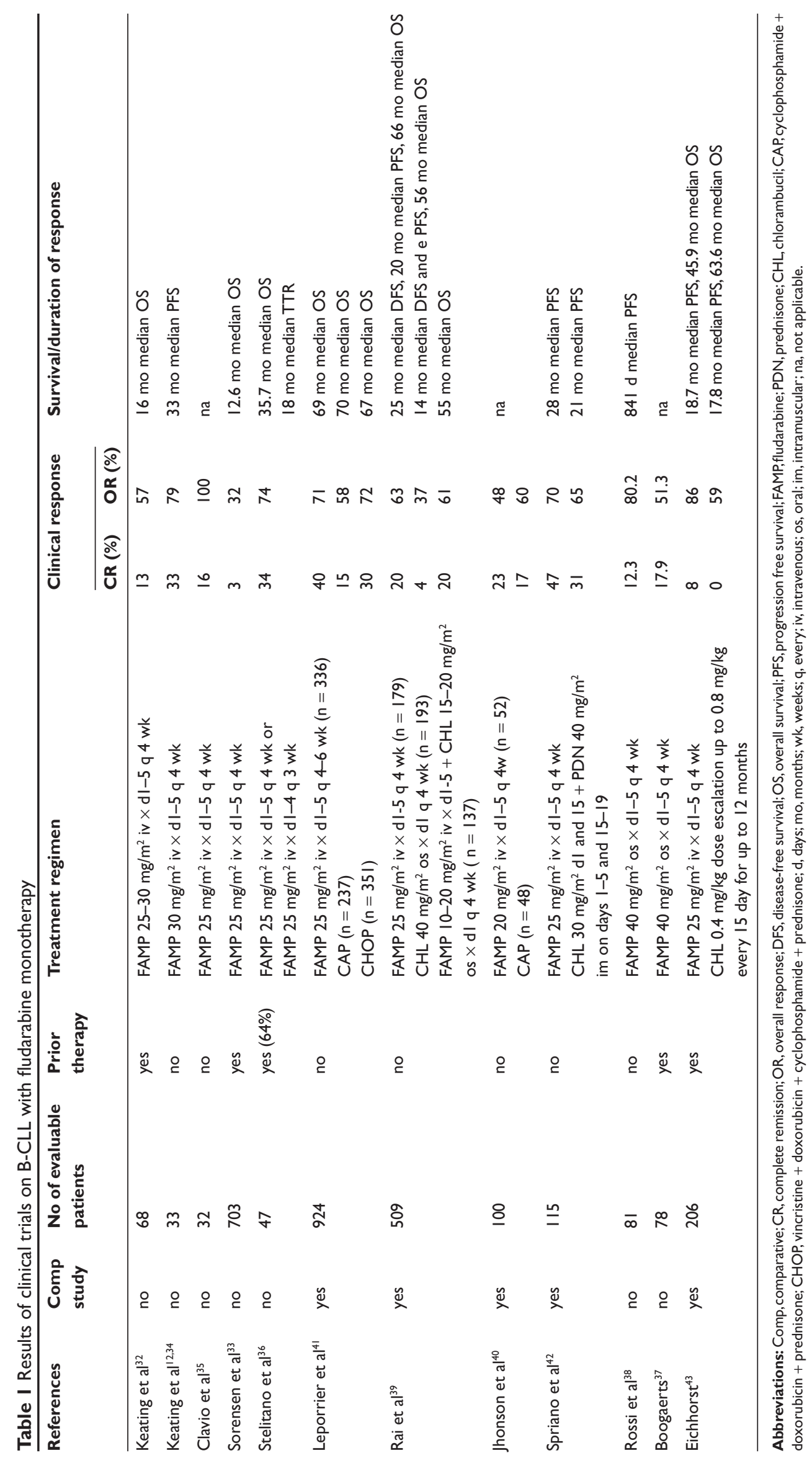


In the first comparative phase III trial, GCLLSG CLL4 study, 362 treatment-naïve patients with advanced B-CLL, were randomly assigned to receive either FAMP $\left(25 \mathrm{mg} / \mathrm{m}^{2} / \mathrm{d}\right.$ for 5 days iv, repeated every 28 days) or FC combination therapy (FAMP $30 \mathrm{mg} / \mathrm{m}^{2} / \mathrm{d}$ plus CTX $250 \mathrm{mg} / \mathrm{m}^{2} / \mathrm{d}$ for 3 days iv, repeated every 28 days). Both regimens were administered up to a maximum of 6 courses.

Patients receiving FC combination chemotherapy showed a significantly higher CR rate (24\%) and OR rate (94\%) compared with FAMP alone (7\% and $83 \%$ ). FC treatment also resulted in longer median PFS (48 vs 20 months) and longer treatment-free survival ( $37 \mathrm{vs} 25$ months). At the time of writing, no difference in median OS has been observed. FC caused significantly more thrombocytopenia and leukocytopenia but did not increase the number of severe infections. ${ }^{59}$ No significant difference was detected in health-related quality of life between FAMP and FC-treated patients. ${ }^{43}$ In a recent update of the outcome of patients enrolled in the CLL4 GCLLSG trial the analysis according to clinical and biologic parameters has been presented. Investigating a specific treatment effect PFS was longer after FC for the following subgroups: unmutated immunoglobulin heavy chain (IgVH) gene, no aberration, del(11q), unmutated TP53, CD38 > 7\%, and beta2microglobulin $<5 \mathrm{mg} / \mathrm{L}$. OS was significantly longer after FC only in the subgroups with 11q-, +12 , and unmutated TP53. However, in comprehensive multivariate analysis of TP53 mutations, del (11q), thymidine kinase $>10$ remained a predictor for PFS and OS independently of the improvement by FC. ${ }^{60}$

Results of a second comparative study were reported by Flinn et al. This is a phase III randomized Intergroup trial comparing FC regimen versus FAMP alone in 278 patients receiving their first chemotherapy regimen for B-CLL. Dosages of FC schedule were the same as the first study. Authors confirmed the superiority of FC arm in terms of OR (74.3\% vs $59.5 \%)$, CR (23.4\% vs $4.6 \%)$ and PFS (31.6 vs 19.2 months). OS was not different between the two arms. Regarding toxicity FAMP and CTX caused additional hematologic toxicity, including more severe thrombocytopenia, but it did not increase the number of severe infections. ${ }^{61}$

The third randomized study was published by Catovsky et al. ${ }^{62}$ Seven hundred and seventy-seven patients with previously untreated B-CLL requiring treatment were randomly assigned to FAMP $\left(25 \mathrm{mg} / \mathrm{m}^{2} / \mathrm{d}\right.$ iv or $40 \mathrm{mg} / \mathrm{m}^{2} / \mathrm{d}$ orally for 5 days) or FC schedule (FAMP $25 \mathrm{mg} / \mathrm{m}^{2} / \mathrm{d}$ iv and CTX $250 \mathrm{mg} / \mathrm{m}^{2} / \mathrm{d}$ iv for 3 days or orally over 5 days with FAMP $24 \mathrm{mg} / \mathrm{m}^{2} / \mathrm{d}$ and CTX $150 \mathrm{mg} / \mathrm{m}^{2} / \mathrm{d}$ ) for 6 courses, or CHL $\left(10 \mathrm{mg} / \mathrm{m}^{2} / \mathrm{d}\right.$ for 7 days) until maximum response or up to 12 courses. Analysis was by intention to treat. There was no significant difference in OS between patients given $\mathrm{FC}$, FAMP or CHL. CR and OR rates were better with FC than with FAMP (CR 38\% vs 15\%, respectively; OR 94\% vs $80 \%$, respectively), which were in turn better than with CHL (CR $7 \%$, OR $72 \%$ respectively). PFS at 5 years was significantly better with FC (36\%) than with FAMP (10\%) or CHL (10\%). $\mathrm{FC}$ was the best combination for all ages, including patients older than 70 years, and in prognostic groups defined by IgVH gene mutation status and cytogenetics. Interestingly, the same PFS has been reported after FAMP alone and after CHL. The dose of CHL used in the LRFCLL4 trial was almost double that used by Rai et al in the earlier comparison, ${ }^{39}$ suggesting that when a higher dose is used FAMP has no advantage over CHL.

A meta-analysis of these data and those of two published phase III trials showed a consistent benefit for the FC regimen in terms of PFS. ${ }^{62}$

FC schedule was also investigated using FAMP and CTX as oral formulation.

Cazin et al reported in 75 treatment-naïve patients with B-CLL an OR and a CR rate of $75 \%$ and $53 \%$ respectively, and a median PFS of 5 years, administering oral FAMP $\left(30 \mathrm{mg} / \mathrm{m}^{2} / \mathrm{d}\right.$ days $\left.1-5\right)$ plus oral CTX $\left(200 \mathrm{mg} / \mathrm{m}^{2} / \mathrm{d}\right.$ days 1-5) every 28 days for 6 courses. ${ }^{63}$

Moreover, Laurenti et al tested the efficacy and safety of oral FAMP and CTX as front-line therapy and assessed the influence of $\mathrm{IgVH}$ gene mutation status, interphase cytogenetic abnormalities, and expression of ZAP-70 and CD38 on clinical outcome. Treatment schedule consisted of oral FAMP $\left(30 \mathrm{mg} / \mathrm{m}^{2}\right)$ and oral CTX $\left(250 \mathrm{mg} / \mathrm{m}^{2}\right)$ for 3 consecutive days every 4 weeks for 6 cycles. High risk cytogenetic group was defined by the abnormality del(11q22.3) or del(17p13.1). Among the 35 evaluable patients, $14(40 \%)$ obtained a CR and $13(37 \%)$ a partial response (PR). The median PFS was 23 months and median time to re-treatment (TTR) was 38 months. A significantly lower OR rate ( $43 \%$ vs $85 \%$ ), a shorter PFS ( 22 vs 27 months), and a shorter TTR (22 vs 40 months) were noticed in the 'high risk' cytogenetic abnormalities group; TTR was also shorter in IgVH-unmutated than in IgVH-mutated patients (26 vs 41 months). ${ }^{64}$

\section{FAMP with anthracyclines or anthracenedione}

The addition of mitoxantrone to FAMP did not markedly increase the response rate to FAMP, but the combination of FAMP with CTX and mitoxantrone (FCM) showed promising results. The efficacy of two slightly different 


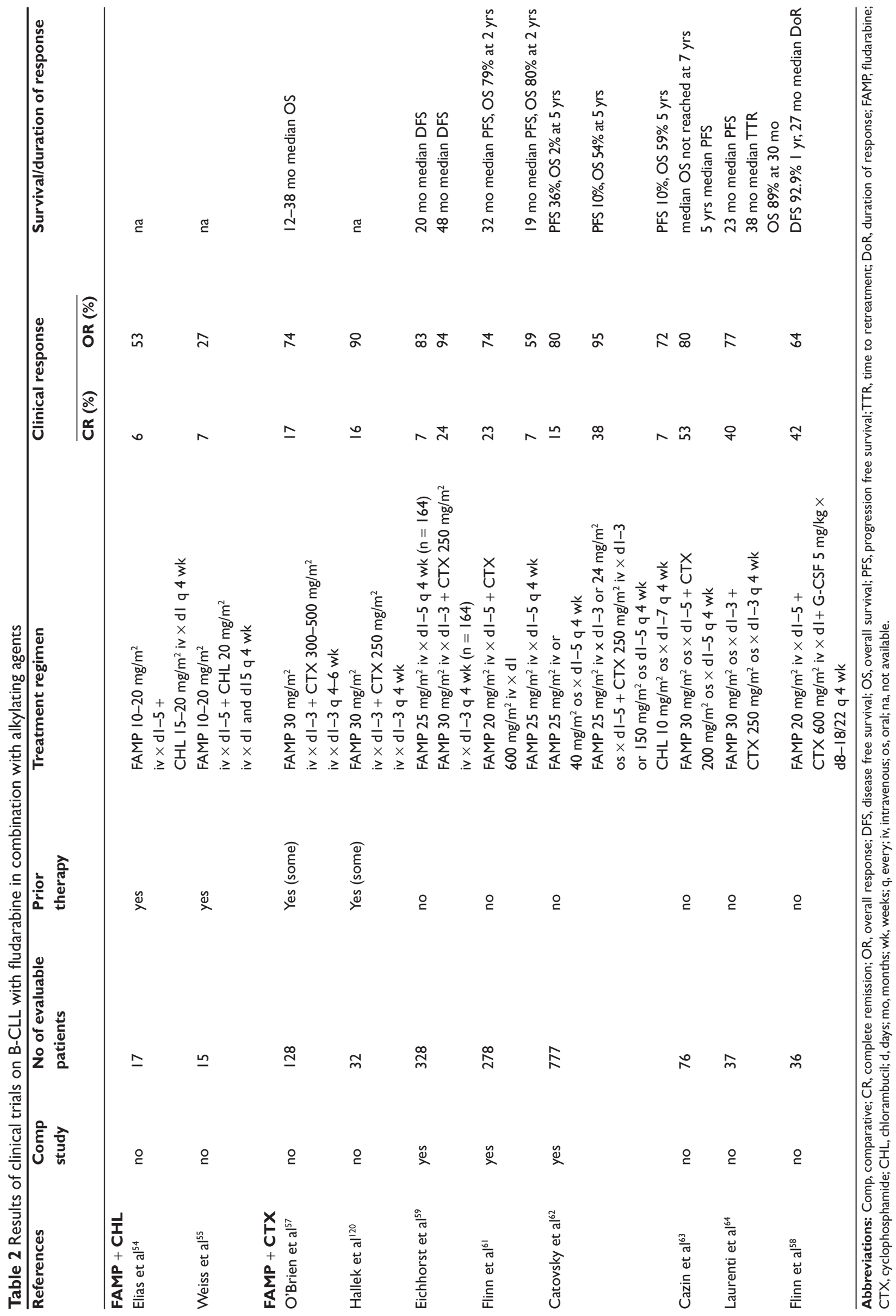


treatment regimens was assessed in a clinical trial in recurrent or resistant B-CLL patients. ${ }^{65}$ Twenty-three patients received iv FAMP $25 \mathrm{mg} / \mathrm{m}^{2}$ on days $1-3$, CTX $600 \mathrm{mg} / \mathrm{m}^{2}$ on day 1 and mitoxantrone $8 \mathrm{mg} / \mathrm{m}^{2}$ on day 1 , at 4-week intervals for up to 6 courses. A further 37 patients received the same FAMP regimen plus CTX $200 \mathrm{mg} / \mathrm{m}^{2} / \mathrm{d}$ on days $1-3$ and mitoxantrone $6 \mathrm{mg} / \mathrm{m}^{2}$ on day 1 . The OR was $78 \%$, including $50 \% \mathrm{CR}$ and 28\% PR. Absence of minimal residual disease (MRD) was detected in $17 \%$ of patients by cytofluorimetric and molecular methods. The median duration of response was 19 months and the actuarial median survival duration was 41 months. The incidence of myelosuppression and infection was noticeably higher in this study (neutropenia or leukocytopenia $=90 \%$ ) with corresponding infection rates of $23 \%$. Recently the same authors reported the results in a larger group of B-CLL patients receiving as initial therapy the same schedule of treatment using mitoxantrone $6 \mathrm{mg} / \mathrm{m}^{2}$. The OR, MRD-negative CR, MRD-positive CR, nodular PR (nPR), and PR rates were 90\%, 26\%, 38\%, 14\%, and 12\%, respectively. Median response duration was 37 months. Patients with del(17p) failed to attain CR. Patients achieving MRD-negative $\mathrm{CR}$ had a longer response duration and OS than patients with an inferior response. Low serum LDH levels, low ZAP-70 expression, and mutated $\operatorname{IgV}(\mathrm{H})$ genes predicted longer response duration. ${ }^{66}$

Comparable results to FCM regimen have been obtained with the combination of FAMP, mitoxantrone, ara-C and dexamethasone (FAND) in previously treated patients (OR $70 \%$, CR 60\%), Although severe neutropenia episodes occurred in $69 \%$ of courses, major infections were seen in only $12 \%$ of these courses. This low incidence is probably explained by the infection prophylaxis with fluconazole, acyclovir, trimethoprim/sulfamethazole and G-CSF. ${ }^{67}$

FAMP has also been investigated in combination with other chemotherapeutic agents. The majority of these studies were small, with less than 50 enrolled patients.

Disappointing results were achieved when FAMP was combined with doxorubicin (with or without prednisone) with an OR rate of $55 \%$ and a CR rate of only $3 \%{ }^{68}$

Higher response rate was reported in untreated and pre-treated patients receiving FAMP associated to epirubicin in a phase II study. ${ }^{69}$

In a phase III, randomized trial, FAMP was compared with FAMP plus epirubicin in the same setting. ${ }^{70}$ Preliminary results in 150 patients showed that the combination achieves statistically higher response rates and longer duration of event free survival; however this does not translate in a statistically significant OS benefit.

\section{FAMP with ara-C with}

\section{or without cisplatin}

FAMP has also been tested in association with ara-C yielding an OR rate of 5\% in FAMP refractory patients. ${ }^{71}$ The addition of cisplatin to this regimen improved the OR slightly to $19 \%$ in a phase II study of 41 pre-treated patients. Notably, the combination of FAMP with ara-C or cisplatin was associated with particularly high toxicities in terms of cytopenia and myelosuppression. ${ }^{72}$

\section{FAMP and non-chemotherapeutic agents}

In the last 2 years the FAMP plus CTX schedule has also been tested in association with new non-chemotherapeutic drugs resulting previously effective in the treatment of other hematological malignancies.

As expression of Bcl-2 protein is associated with chemotherapy resistance and decreased survival in B-CLL, O'Brien et al evaluated whether oblimersen, antisense oligonucleotides would improve response to FC chemotherapy in patients with relapsed or refractory B-CLL.

Two hundred and forty-one patients receiving at least one prior FAMP-containing regimen were randomly assigned to 28-day cycles of FAMP $25 \mathrm{mg} / \mathrm{m}^{2} / \mathrm{d}$ plus CTX $250 \mathrm{mg} / \mathrm{m}^{2} / \mathrm{d}$ administered iv for 3 days with or without oblimersen $3 \mathrm{mg} / \mathrm{kg} / \mathrm{d}$ as a 7-day continuous iv infusion (beginning 4 days before chemotherapy) for up to 6 cycles.

$\mathrm{CR} / \mathrm{nPR}$ rates were significantly higher in the oblimersen $\operatorname{arm}(17 \%$ vs $7 \%)$ and achievement of $\mathrm{CR} / \mathrm{nPR}$ was correlated with both an extended time to progression and survival. In patients who remained sensitive to FAMP, oblimersen was associated with a 4-fold increase in the $\mathrm{CR} / \mathrm{nPR}$ rate and a significant survival benefit. ${ }^{73}$

Thalidomide has been shown to inhibit production of TNF-alpha. Elevated levels of TNF-alpha have been associated with progressive disease in patients with B-CLL. Chanan Khan et al conducted a phase $1 / 2$ clinical trial to determine the safety and efficacy of combining thalidomide with FAMP in patients with treatment-naïve B-CLL. Patients received 6 months of continuous daily thalidomide with standard monthly doses of FAMP. Three dose levels of thalidomide $(100,200$, and $300 \mathrm{mg})$ were studied. Thirteen patients were enrolled in the phase 1 component of the study. Dose-limiting toxicity was not reached. OR rate was $100 \%$ with $55 \%$ of patients achieving CR. At a median follow-up of 15 months none of the patients had had a relapse and the median time to disease progression had not yet been reached. Responses were noted at all dose levels. ${ }^{74}$ Disappointing results have been reported in a small Italian study in which 5 pre-treated B-CLL 


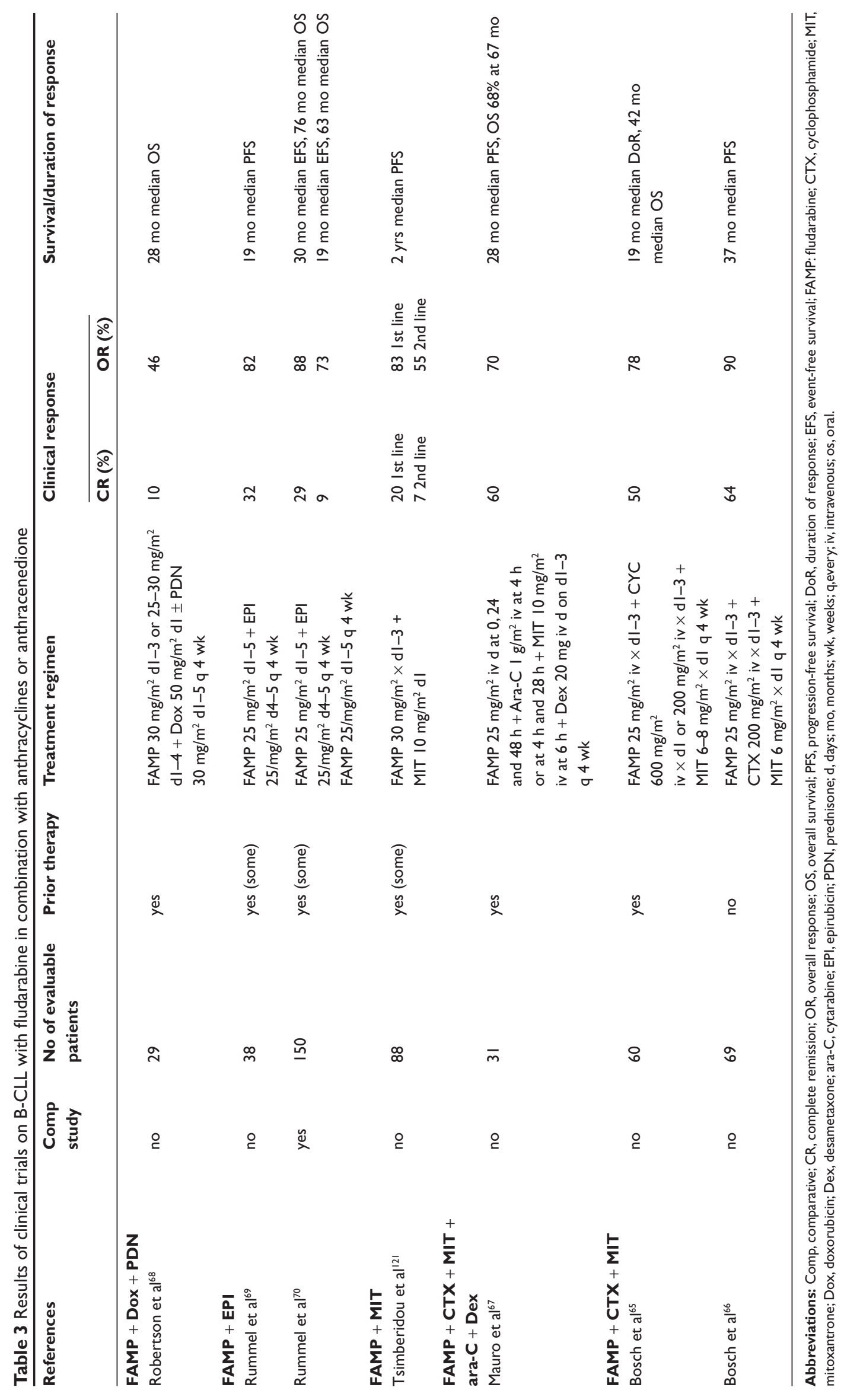


Table 4 Results of clinical trials on B-CLL with fludarabine with ara-C with or without cisplatin

\begin{tabular}{|c|c|c|c|c|c|c|c|}
\hline \multirow[t]{2}{*}{ References } & \multirow{2}{*}{$\begin{array}{l}\text { Comp } \\
\text { study }\end{array}$} & \multirow{2}{*}{$\begin{array}{l}\text { No of evaluable } \\
\text { pts }\end{array}$} & \multirow{2}{*}{$\begin{array}{l}\text { Prior } \\
\text { therapy }\end{array}$} & \multirow[t]{2}{*}{ Treatement regimen } & \multicolumn{2}{|c|}{ Clinical response } & \multirow{2}{*}{$\begin{array}{l}\text { Survival/duration } \\
\text { of response }\end{array}$} \\
\hline & & & & & CR (\%) & OR (\%) & \\
\hline FAMP + ara-C & no & 15 & yes & FAMP $30 \mathrm{mg} / \mathrm{m}^{2} \mathrm{dl}+$ ara-C & 0 & 5 & 9 mo median OS \\
\hline Gandhi et al ${ }^{71}$ & & & & $500-1000 \mathrm{mg} / \mathrm{m}^{2} \mathrm{dl} \mathrm{q} 4 \mathrm{wk}$ & & & \\
\hline FAMP + ara-C + Cis & no & 41 & yes & FAMP $30 \mathrm{mg} / \mathrm{m}^{2} \mathrm{~d} 4+$ Cis $25 \mathrm{mg} / \mathrm{m}^{2}$ & 0 & 19 & 6 mo median OS \\
\hline Giles et a $7^{72}$ & & & & $\mathrm{dl}-4 \pm$ ara-C $500 \mathrm{mg} / \mathrm{m}^{2} \mathrm{~d} 4 \mathrm{q} 4 \mathrm{wk}$ & & & \\
\hline
\end{tabular}

Abbreviations: Comp, comparative; CR, complete remission; OR, overall response; OS, overall survival; FAMP, fludarabine; ara-C, cytarabine; Cis, cisplatin; d, days; mo, months; wk, weeks; q, every; iv, intravenous; os, oral.

patients were enrolled. Four patients had to be withdrawn from the study due to disease progression in 3 cases while a severe neurological toxicity was detected in 1 patient. $^{75}$

\section{FAMP in combination with monoclonal antibodies}

The emergence of monoclonal antibodies has expanded the possibilities and strategies for therapy in patients with B-CLL.

There are several reasons for combining chemotherapy with monoclonal antibodies. First, there is little overlapping toxicity. Second, chemotherapy and monoclonal antibodies cause cell death by different mechanisms, and B-CLL cells that are resistant to one mechanism of cell killing may be susceptible to the other. Third, there is preclinical evidence to suggest that chemotherapy and monoclonal antibodies may act in a synergistic manner. Rituximab is a chimeric monoclonal antibody that binds to CD20 and is currently approved for the treatment of patients with relapsed lowgrade lymphoma. Alemtuzumab is an anti-CD52 antibody approved for B-CLL patients who have failed prior therapy with FAMP. More recently FDA granted regular approval and expanded labeling for alemtuzumab as single-agent treatment for B-CLL.

Rituximab has limited activity as a single agent in B-CLL, with reported OR rates ranging from $7 \%$ to $35 \%$ in relapsed patients. ${ }^{76,77}$ Dose intensification strategies have been used, with higher response rates achieved. However, the majority of responses were partial and of brief duration. ${ }^{78}$

Because of these findings, rituximab is more often used in combination with other chemotherapeutic agents, such as FAMP or FAMP plus CTX. ${ }^{79-81}$

Cancer and Leukemia Group B (CALGB) and the US Intergroup investigated in multicenter phase 2 trial (CALGB 9712) safety and efficacy of a immuno-chemotherapeutic regimen combining FAMP and rituximab (FR) in treatmentnaive B-CLL. Patients were randomized to receive either 6 courses of FAMP (one course every 28 days) concurrently with rituximab followed 2 months later by 4-weekly doses of rituximab for consolidation therapy or sequential FAMP alone followed 2 months later by rituximab consolidation therapy. In this study rituximab administered concurrently with FAMP in previously untreated B-CLL patients demonstrates marked clinical efficacy in terms of OR $(90 \%$ vs $77 \%$ ) and CR (47\% vs $28 \%$ ) rates and acceptable toxicity. However no differences were detected in term of PFS and OS between the two arms. ${ }^{79}$

The same authors retrospectively compared efficacy data of the CALGB 9712 study with the CALGB 9011 study that compared FAMP as single agent to CHL. In multivariate analyses controlling for pre-treatment characteristics, the patients receiving FAMP and rituximab had a significantly better PFS and OS than patients receiving FAMP therapy. Two-year PFS probabilities were 0.67 vs 0.45 , and 2 -year OS probabilities were 0.93 vs 0.81 . Infectious toxicity was similar between the two treatment approaches. ${ }^{82}$ These comparative data are retrospective and could be confounded by differences in supportive care or dissimilar enrolment of genetic subsets on each trial.

A multivariate analysis examining the type of treatment (addition or not of rituximab) and other pre-treatment clinical and laboratory features demonstrated that inclusion of rituximab was as good as or better than leukocytosis and age at predicting PFS and OS. ${ }^{82}$

More recently the M.D. Anderson Cancer Group published results obtained with the combination of FAMP, CTX and rituximab (FCR) in previously treated B-CLL patients.

Treatment consisted of rituximab $375 \mathrm{mg} / \mathrm{m}^{2}$ day 1 of course 1 and $500 \mathrm{mg} / \mathrm{m}^{2}$ day 1 of courses 2 to 6; FAMP $25 \mathrm{mg} / \mathrm{m}^{2} / \mathrm{d}$ days 2 to 4 of course 1 and days 1 to 3 of courses 2 to 6 ; and CTX $250 \mathrm{mg} / \mathrm{m}^{2} / \mathrm{d}$ days 2 to 4 of course 1 and days 1 to 3 of courses 2 to 6 . Courses were repeated every 4 weeks. CR was achieved in $25 \%$ of 177 patients enrolled, with an OR rate of $73 \%$. Molecular remission was achieved in a third of patients who obtained CR. ${ }^{80}$ 
Keating et $\mathrm{a}^{81}$ tested FCR schedule in 224 previously untreated B-CLL patients. Results and safety were historically compared with the previously reported data on a group of patients treated with $\mathrm{FC} .{ }^{57}$ The OR and CR rates were $95 \%$ and $70 \%$ respectively. The $\mathrm{CR}$ rate compared favorably with that achieved in the historical experience with FC ( $35 \%$ vs $70 \%$ ), while no differences were detected in OR rate ( $88 \%$ vs $95 \%$ ). Two thirds of patients, receiving FCR schedule, evaluated with two-color flow cytometry, had less than $1 \% \mathrm{CD}^{+} / \mathrm{CD} 9^{+}$ coexpressing cells in bone marrow after therapy. Recently the authors published an update of long-term results reporting a 6 -year overall and failure-free survival of $77 \%$ and $51 \%$, respectively. Median time to progression was 80 months.

Pre-treatment characteristics independently associated with inferior response were age 70 years or older (14\% of patients), beta2-microglobulin twice the upper limit of normal $(2 \mathrm{~N})$ or more ( $43 \%$ of patients), white cell count $150 \times$ $10 \% / \mathrm{L}$ or more (17\% of patients), abnormal chromosome 17 ( $4 \%$ of patients), and LDH $2 \mathrm{~N}$ or more ( $2 \%$ of patients). No pre-treatment characteristic was independently associated with decreased CR duration. ${ }^{83}$

Recently the same authors reported no significant impact of the mutational status on the CR rate and on long-term survival in patients treated with FCR. However in patients with unmutated $\mathrm{IgVH}$ a shorter remission duration was observed. $^{84}$

Interestingly in a multivariate analysis of patients receiving FAMP-based therapy at M.D. Anderson Cancer Center Group, FCR therapy emerged as the strongest independent determinant of survival..$^{83}$

In order to validate the observation of a single center study that FCR combination improved the outcome of untreated B-CLL patients the GCLLSG initiated a multicenter, multinational phase III trial to evaluate the efficacy and tolerability of FCR vs FC as first-line treatment of patients with advanced B-CLL.

In this study 817 patients were enrolled between July 2003 and March 2006. After a median observation time of 25.5 months, 761 patients (FCR 390; FC 371) were evaluable for response and 787 patients (FCR 400; FC 387) for PFS and all for OS. The OR and CR rates were significantly higher in the FCR arm (95\% and 52\%) than in FC (88\% and $27 \%$ ). PFS was $76.6 \%$ at 2 years in the FCR arm and $62.3 \%$ in the FC arm with a trend for an increased OS rate in the FCR arm ( $91 \%$ vs $88 \%$ at 2 years $){ }^{85}$

The major toxicity related to FCR treatment was grade 3/4 neutropenia while persistent cytopenia following completion of therapy and lasting more than 3 months was reported in $19 \%$ of patients treated. However, following recovery of blood counts, recurrent late cytopenia episodes occurred in $28 \%$ of cases, predominantly during the first year of remission, with 1 and 6 year incidences of $18 \%$ and $23 \%$, respectively. ${ }^{83}$ One approach to decrease neutropenia without compromising efficacy could be by reducing the doses of FAMP and CTX and increasing the cumulative dose of rituximab. Foon et al conducted a phase II study for previously untreated advanced B-CLL patients using a so-called FCR-Lite schedule (FAMP $20 \mathrm{mg} / \mathrm{m}^{2} / \mathrm{d}$ days $1-3$, CTX $150 \mathrm{mg} / \mathrm{m}^{2} / \mathrm{d}$ days $1-3$, rituximab $500 \mathrm{mg} / \mathrm{m}^{2} / \mathrm{d}$ days 1 and days 14 every 4 weeks; maintenance rituximab $500 \mathrm{mg} / \mathrm{m}^{2}$ every 3 months until progression).

Fifty patients were enrolled to receive treatment and 48 were evaluable for response. Among them $\mathrm{CR}$ rate was $77 \%$, PR rate was $23 \%$ with an OR rate of $100 \%$. Patients who achieved CR were tested by two-color flow cytometry and $97 \%$ of patients had $<1 \% \mathrm{CD}^{+} / \mathrm{CD} 19^{+}$cells in their bone marrow after therapy. This experience suggests that FCR-Lite is highly effective with considerably less grade 3/4 neutropenia than standard FCR. Complete responders had no detectable CD5+/CD19+ cells in their bone marrow following FCR-Lite. ${ }^{86}$

As previously mentioned a synergistic effect has been demonstrated between FAMP, ara-C and cisplatin. ${ }^{72}$ The M.D. Anderson Cancer Group explored the efficacy of FAMP plus rituximab when associated to oxaliplatin and ara-C in OFAR regimen that consisted of increasing doses of oxaliplatin $\left(17.5,20\right.$, or $25 \mathrm{mg} / \mathrm{m}^{2} / \mathrm{d}$ on days $1-4$, phase I), FAMP $30 \mathrm{mg} / \mathrm{m}^{2} / \mathrm{d}$ on days 2 to 3 , ara-C $1 \mathrm{~g} / \mathrm{m}^{2} / \mathrm{d}$ on days 2 to 3 , rituximab $375 \mathrm{mg} / \mathrm{m}^{2}$ on day 3 of cycle 1 and day 1 of subsequent cycles, and pegfilgrastim $6 \mathrm{mg}$ on day 6 , every 4 weeks for a maximum of 6 courses.

In a phase I-II trial 50 patients were treated (20 patients had Richter's syndrome, and 30 had a FAMP refractory B-CLL) with OFAR schedule. This regimen was highly active with an OR rate of 50\% in Richter's syndrome and of $33 \%$ in FAMP-refractory B-CLL. Satisfactory response was also achieved in 7 of the 20 patients with $17 \mathrm{p}$ deletion (35\%) and in 2 of 7 patients with 11q deletion (29\%). ${ }^{87}$

Based upon the excellent previously mentioned results obtained with FCM, ${ }^{88}$ the same group of authors have built up a new chemoimmunotherapy combination with rituximab plus FCM (R-FCM). In a phase II study 72 patients under the age of 70 with active B-CLL according to NCI and IWCLL criteria received R-FCM regimen as initial treatment followed by a maintenance therapy phase consisting of rituximab every 3 months for 2 years. Although based on two 
different phase II studies that preclude a completely valid statistical comparison, the CR rate obtained with R-FCM ( $82 \%$, of which $46 \%$ MRD-negative CR) favorably compares with that achieved with FCM (CR 64\%, MRD-negative CRs $38 \%$ ). In summary the $82 \%$ CR rate obtained with R-FCM is among the highest ever reported for any form of therapy for B-CLL and treatment toxicity was acceptable and manageable. ${ }^{88}$ Based on these results, R-FCM warrants further investigation, particularly in randomized clinical trials.

In the scene of monoclonal antibodies available for B-CLL treatment alemtuzumab has certainly shown superior activity when compared with rituximab as monotherapy. In addition, alemtuzumab is most effective in reducing leukemia counts and bone marrow disease and less effective in shrinking bulky lymphadenopathy. Alemtuzumab has been studied in FAMP refractory B-CLL patients, ${ }^{89}$ in previously untreated patients, ${ }^{90}$ in patients with MRD persistence after FAMP-based regimen, ${ }^{91,92}$ and concurrent with FAMP ${ }^{93,94}$ and rituximab. ${ }^{95,96}$ Apart from the infusional reaction related to iv administration of alemtuzumab, the development of opportunistic infections are reported. Antibacterial and antiviral prophylaxis is recommended in all patients receiving alemtuzumab therapy.

The first experiment was conducted by Kennedy et al who treated 6 patients with B-CLL who were refractory to both alemtuzumab and FAMP used as single agents, and found that 5 of 6 patients responded to combination therapy, including 1 CR. However, long-term follow-up is not yet available. The toxicity of this regimen was acceptable, with none of the patients developing serious infections. ${ }^{93}$

Elter et al extended these observations to a larger cohort of patients with relapsed or refractory B-CLL. Thirty-six patients were treated with alemtuzumab $30 \mathrm{mg} / \mathrm{d}$ iv and FAMP $30 \mathrm{mg} / \mathrm{m}^{2} / \mathrm{d}$ iv on 3 consecutive days every 28 days for a total of 6 cycles ( 4 cycles in the first 14 patients).

The OR and CR rates were $83 \%$ and $30 \%$ respectively. The median OS was 35.6 months for all patients, with a time to progression of 22 months in patients who achieved a CR and 13 months for patients who achieved a PR. The treatment was well tolerated with acceptable infectious morbidity. ${ }^{94}$ Based upon these results, a phase III study comparing FAMP alone to FAMP plus alemtuzumab is currently underway in Europe.

Subsequently the M.D. Anderson group explored combination of alemtuzumab plus FAMP with CTX and rituximab with the goal of improving CR rate and eliminating MRD. Wierda et al reported the preliminary results of a phase II trial in which 31 patients with pre-treated B-CLL were treated with CTX (250 mg/m²/d days 3-5), FAMP (25 mg/m²/d days 3-5 i.v.) alemtuzumab (30 $\mathrm{mg}$ day $1,3,5)$ and rituximab (500 mg/m² day 2), every 28 days for 6 cycles. Twenty-one patients were evaluable for response and after a median number of 3 cycles (range 1-6) the OR rate was 52\%, with 3 patients achieving a CR (14\%) and 8 patients achieving a PR (38\%). CMV reactivation was noted in 5 of 21 patients. ${ }^{95}$ Based upon these results, CFAR regimen was tested in a larger phase II study in patients with high risk and NCI indication for frontline therapy. OR and CR rates were 95\% and $71 \%$ respectively. All patients in CR and nPR and 3 of 4 in PR were free of disease in the bone marrow by threecolor flow cytometry. There was no significant correlation between CR or OR and Rai stage, IgVH mutation status, FISH status, or ZAP70 or CD38 expression. Grade 3 or 4 neutropenia and thrombocytopenia were seen in $27 \%$ and $7 \%$ of courses respectively and major infections were seen in $2 \%$ of courses. ${ }^{96}$

Montillo et al reported interesting results combining FAMP plus alemtuzumab with CTX (FCC schedule) in a phase II study in patients with B-CLL with relapsed or refractory disease after at least one line of treatment. Subcutaneous route of administration of alemtuzumab was adopted in this trial. The FCC regimen consisted of FAMP $40 \mathrm{mg} / \mathrm{m}^{2} / \mathrm{d}$ oral days 1-3, CTX $250 \mathrm{mg} / \mathrm{m}^{2} / \mathrm{d}$ oral days $1-3$ and alemtuzumab 10 to $20 \mathrm{mg}$ subcutaneous days $1-3$. This combination was repeated on day 29 for up to 6 cycles. Among the 25 patients enrolled OR rate was $79 \%$, with $37 \%$ patients achieving CR. Grade III-IV neutropenia episodes were observed in $43 \%$ of the administered courses while grade III-IV thrombocytopenia episodes were detected only in $8 \%$ of cycles. Four major infections were recorded. ${ }^{97}$ Similar OR and CR rate have been obtained by Elter with the same combination. ${ }^{98}$ Two phase III studies comparing FC to FC plus alemtuzumab and FCR to FC plus alemtuzumab are currently ongoing in Europe by HOVON and GOELAMS respectively.

Another monoclonal antibody tested in B-CLL is Lumiliximab an anti-CD23 with human IgG1 constant regions and macaque variable regions.

Preclinical data demonstrated that lumiliximab enhanced both FAMP- and rituximab- mediated apoptosis in B-CLL cells.

Preliminary results of phase $1 / 2$, open-label, dose-escalation, multicenter study evaluating lumiliximab + FCR for relapsed CD23+ B-CLL have been reported. Treatment has been completed and follow-up is ongoing. Thirty-one patients received either $375 \mathrm{mg} / \mathrm{m}^{2}$ or $500 \mathrm{mg} / \mathrm{m}^{2}$ of lumiliximab in 
combination with a 28-day cycle of FCR for up to 6 cycles. The most common adverse events included nausea $(77 \%)$, pyrexia (61\%), chills (55\%), neutropenia (55\%), and fatigue (48\%). Twenty patients (65\%) experienced a Grade III or IV event. CR was achieved in $48 \%$ of patients with an OR rate of $71 \%$. A comparison with data reported using FCR alone in relapsed or refractory B-CLL ${ }^{80}$ demonstrated that Lumiliximab + FCR has an acceptable safety profile. Moreover, it does not appear to increase the toxicity (including myelosuppression) of the FCR regimen, and compares favorably with the $\mathrm{CR}$ rate of the FCR regimen alone. ${ }^{99}$

Studies testing FAMP combined with monoclonal antibodies are listed in Table 5 .

\section{FAMP in allogeneic stem cell transplantation}

Allogeneic stem cell transplantation (alloSCT) is used for the treatment of various hematological malignancies. The standard approach has involved the use of a conditioning regimen, comprising myeloablative doses of chemo-radiotherapy, to eradicate the underlying malignancy and eliminate the host's bone marrow in preparation for allogeneic graft, which functions primarily as a bone marrow rescue. More recently it has been suggested that the complete eradication of tumor cells is largely mediated by an immune-mediated destruction of malignant cells by donor lymphocytes, termed the graft-versus-leukemia (GVL) or graft-vs-tumor (GVT) effect. Replacing high-dose myeloablative therapy with a nonmyeloablative conditioning regimen would allow treatment of those patients who are too old or medically unfit to qualify for conventional alloSCT. ${ }^{100}$ The aim of non-myeloablative alloSCT is to use a low intensity preparative regimen to induce sufficient immunosuppression in the recipient to allow engraftment of allogeneic stem cells to prevent graft rejection. The non-myeloablative regimen does not completely eliminate host-derived cells, but over a period of time allogeneic lymphocytes act to eliminate residual hematopoietic and malignant cells. The drugs used in non-myeloablative conditioning regimens are generally chosen because they have some activity against the target malignancy and also provide sufficient immunosuppression to allow engraftment of allogeneic stem cells.

FAMP has been widely used in non-myeloablative conditioning regimens because of its immunosuppressive and antitumor activity. FAMP is often combined with a variety of other cytotoxic agents, such as melphalan, CTX, ara-C and busulfan, or with low-dose total body irradiation, with the aim of inducing enough immunosuppression to allow successful engraftment and to exert some pretransplant anti-tumor activity. Non-myeloablative combination regimens with FAMP and other cytotoxic agents have been used in patients with various hematological diseases, including AML, chronic myeloid leukemia (CML), B-CLL, non-Hodgkin's lymphoma (NHL), Hodgkin's disease (HD), acute lymphoid leukemia (ALL) and multiple myeloma. ${ }^{101-104}$ The objective of achieving donor engraftment using a FAMP-based nonmyeloablative conditioning regimen was achieved in all the studies reviewed. More recently, the addition of the monoclonal antibody alemtuzumab to a FAMP-based protocol has been shown to reduce the incidence of GVHD, warranting further investigation in a randomized trial. ${ }^{105}$

The main studies using FAMP-based regimen as nonmyeloablative conditioning in B-CLL patients are reported in Table 6

\section{Adverse events}

The most frequent adverse events associated with standarddose iv FAMP regimens are myelosuppression (neutropenia, thrombocytopenia and anemia) and infection (typically respiratory tract infections and fever). Myelosuppression is the major dose-limiting adverse effect. NCI grade IV hematological toxicity was reported in $43 \%$ of patients receiving FAMP monotherapy for advanced-stage refractory B-CLL. ${ }^{33}$ In large-scale randomized studies, neutropenia, thrombocytopenia and anemia (WHO grade III/IV) occurred in 19\%, $14 \%$ and $7 \%$ of FAMP treatment cycles, respectively, and affected $38,15 \%$ and $18 \%$ of patients, respectively, during the first 6 treatment cycles. ${ }^{40}$ Severe (Grade III or IV) neutropenia tended to be more frequent with FAMP than with CHL (27\% vs 19\%). Treatment with FAMP leads to a decrease in the $\mathrm{CD}^{+} / \mathrm{CD}^{+}$ratio for an extensive period of time, exceeding even 24 months. ${ }^{106}$ In consequence, infections, including opportunistic ones, are frequent events and infections with fatal outcome have been reported. ${ }^{107,108}$ FAMP-associated infection affects approximately 5\% of patients with B-CLL, ${ }^{41}$ is accompanied by a sustained fall in T-cell numbers, ${ }^{44}$ and is exacerbated by coadministration of prednisone. ${ }^{109}$ Prolonged immunosuppression related to FAMP treatment may increase the risk of second malignancies. A retrospective analysis performed by Cheson et al in which they compared secondary tumours in B-CLL patients treated with FAMP, shows that this agent does not increase the risk of secondary neoplasms. ${ }^{110}$

Also MDS and secondary AML (sAML) are rarely reported following FAMP monotherapy and no such cases were reported in 3 large cohorts of patients receiving FAMP 


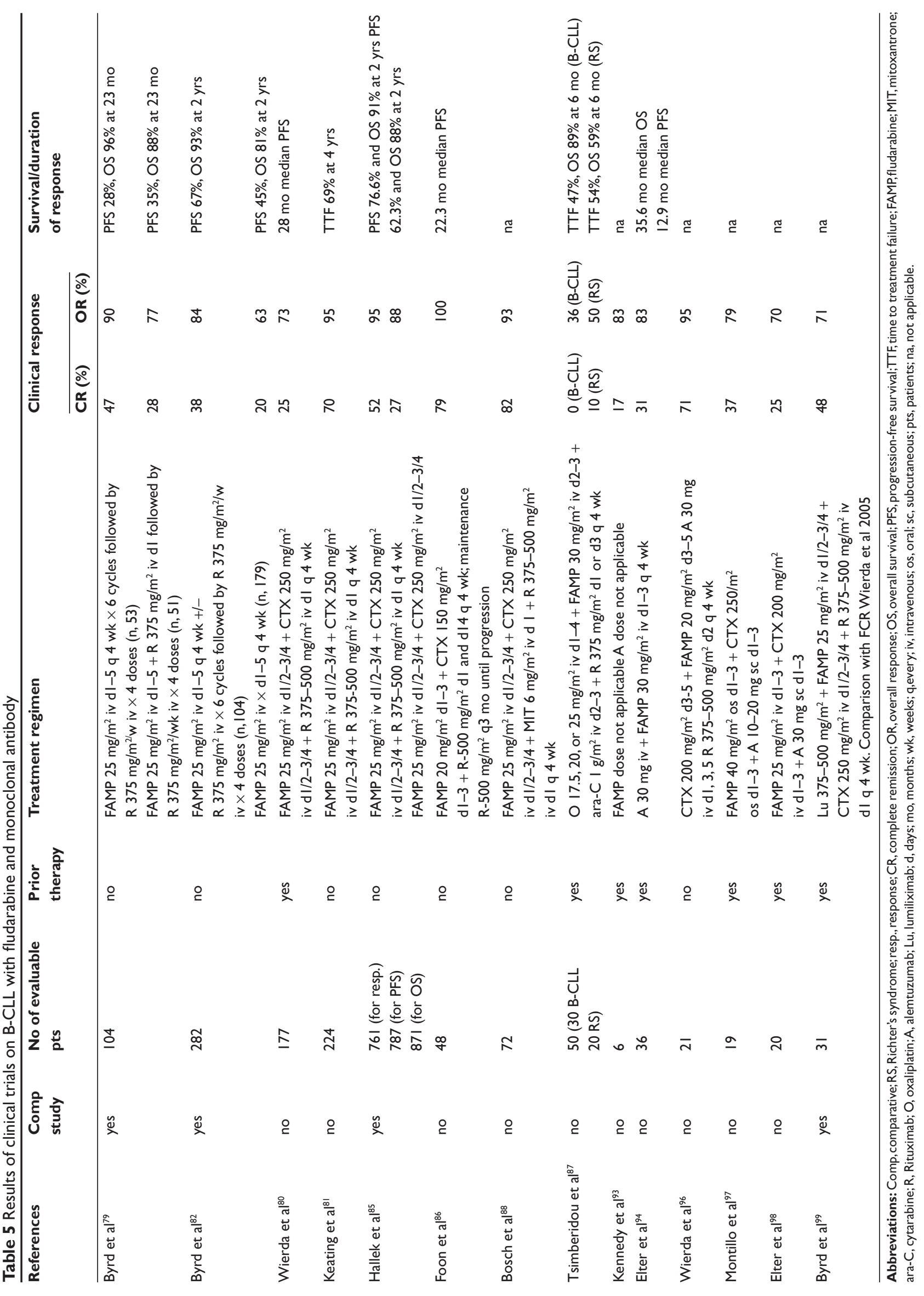


as initial therapy for B-CLL ${ }^{13,40,41}$ and only a single case was recorded among 724 patients receiving FAMP as salvage therapy for B-CLL. ${ }^{110}$ However, the combination of FAMP with CTX or other DNA damaging agents or following intensification with transplant procedure may increase the risk of MDS/sAML due to synergistic effects in the induction and inhibition of DNA damage. ${ }^{11-113}$

Some reports suggest that FAMP may induce autoimmune hemolytic anemia (AIHA) in patients with B-CLL despite the reduction in leukemic clone. ${ }^{114}$ In the study performed by French Cooperative Group newly occuring AIHA was observed in only 2 patients treated with FAMP ${ }^{40}$ Leporrier et al reported true AIHA only in 3\% of the patients treated with $\mathrm{CHOP}, 1.5 \%$ treated with CAP and $1.5 \%$ treated with FAMP ${ }^{41}$ Also in the LRFCLL4 trial the frequency of AIHA at completion of treatment was no different between CHL (12\%) and FAMP (11\%), and the lowest rate was noted after FAMP plus CTX administration (5\%). ${ }^{62}$

These findings suggest that FAMP plus CTX might have a protective effect, supporting similar observations of a study by the GCLLSG. ${ }^{59}$ Although, the results of the prospective multicenter randomized studies do not support the conclusion that the risk of AIHA is higher in the B-CLL patients treated with FAMP than in patients treated with CHL or other alkylating agents based regimens, the AIHA after FAMP could be more severe and more difficult to treat as suggested by the fatal events observed in the LRFCLL4 trial. ${ }^{62}$

Pure red cell aplasia (PRCA) occurs in approximately $5 \%$ of B-CLL patients, most often in the course of disease, but also at presentation. The influence of FAMP on PRCA in patients with B-CLL has not been definitely defined yet.

The influence of prior treatment on the development of an aggressive NHL during the course of B-CLL (Richter's syndrome) is unclear. Cheson et al found 18 (3.0\%) patients with NHL among 595 patients treated with FAMP. ${ }^{110}$ In a retrospective analysis of 1487 B-CLL patients Richter's syndrome was observed in $1 \%$ of cases in a group treated with cladribine, $0.9 \%$ in a group treated with alkylating agents and $0.6 \%$ in a group treated with cladribine + alkylating agents. ${ }^{115}$ The estimation of real incidence of Richter's syndrome in patients treated with purine analogs needs further observation and longer follow-up.

Although there are reports documenting that FAMP impairs PBSC mobilization, this is still a much-discussed issue. It has been shown that other factors may affect the ability to mobilize stem cells: the number of prior therapeutic regimens, the disease stage at the time of mobilization, the 
quality of response to FAMP. An early report from the EBMT indicated that FAMP did not impair progenitor cell mobilization, although better results were obtained early in the course of the disease and after two months from the last cycle of treatment. ${ }^{116}$ However, 2 reports have identified that prior FAMP therapy in patients with lymphoprolipherative disease may be associated with difficulties in obtaining adequate progenitor cell numbers. ${ }^{17,118}$ It is possible that more effective mobilization strategies, and also more intensive cytoreductive therapy to achieve better disease control prior to attempting mobilization might help yield an adequate harvest in an even greater proportion of patients. ${ }^{119}$

\section{Conclusion}

The increased knowledge of the biological and clinical features of B-CLL has been mirrored by the development of therapeutic agents that are more active than previous approaches. In this setting, FAMP has made the most significant impact on how we manage B-CLL today. Compared to traditional strategies, FAMP has improved remission rates and lengthened response duration, and has rapidly become established as the gold standard of care in B-CLL.

Furthermore FAMP has been shown to have a synergistic/ biochemical modulating effect, with other chemotherapeutic agents and, more recently, with monoclonal antibodies. Thus, FAMP serves as a paradigm for the development of anticancer treatment with rational combinations in modern therapeutic regimens.

The data reviewed indicate that FAMP administered in combination regimens may improve quality and rates of response, compared with FAMP in monotherapy in both pre-treated and untreated B-CLL patients. Although FC combination demonstrated exciting results in terms of $\mathrm{OR}$ and CR rates ranging from $74 \%$ to $94 \%$ and from $23 \%$ to $38 \%$ respectively, no difference was detected in survival.

Recently, eradication of MRD in B-CLL has been reported to be associated with prolonged survival. The development of such a wide variety of novel 'targeted' therapies for B-CLL and in particular of monoclonal antibody promises to make the goal of achieving MRD-negative remissions a reality for a large proportion of patients. The combination of FAMP/ $\mathrm{CTX} /$ mitoxantrone and FAMP combinations with rituximab or alemtuzumab, might be promising, since a relevant number of complete molecular remissions are achieved with these drugs. The precise role of FAMP combinations within the overall treatment strategy remains to be determined. However, it is worth mentioning the results recently reported of trial CLL8 GCLLSG suggesting that FCR combination might become the new standard first-line treatment for physically fit B-CLL patients.

Combination of FAMP with other drugs rather than chemotherapeutic agents such as oblimersen or thalidomide warrants further investigation.

Increased clinical use of FAMP has highlighted its potential toxic effects, primarily myelo- and immuno-suppression. However, myelosuppression can be managed, even with the use of growth factors, and infectious complications can be prevented with adequate prophylaxis.

The most recent improvement in FAMP therapy is the development of an oral formulation with equivalent efficacy and tolerability to the iv preparation, coupled with the advantage of improved convenience of administration (for both patient and physician) and potentially superior cost effectiveness.

\section{Disclosures}

The authors have no conflicts of interest to declare.

\section{References}

1. CLL Trialists' Collaborative Group. Chemotherapeutic options in chronic lymphocytic leukemia: a meta-analysis of the randomized trials. J Natl Cancer Inst. 1999;91:861-868.

2. Barrueco JR, Jacobsen DM, Chang C-H, et al. Proposed mechanism of therapeutic selectivity of 9- $\beta$-D-arabinofuranosyl-2-fluoroadenine against murine leukemia based upon lower capacities for transport and phosphorylation in proliferative intestinal epithelium compared to tumor cells. Cancer Res. 1987;47:700-706.

3. Ross SR, McTavish D, Faulds D. Fludarabine: a review of its pharmacological properties and therapeutic potential in malignancy. Drugs. 1993;45:737-759.

4. Plunkett W, Gandhi V. Cellular metabolism of nucleoside analogs in CLL: implications for drug development. In: Cheson B, editor. Chronic lymphocytic leukemia - scientific advances and clinical developments. New York: Marcel Dekker. 1992. p. 197-219.

5. Plunkett W, Gandhi V, Huang P, et al. Fludarabine: pharmacokinetics, mechanisms of action, and rationales for combination therapy. Semin Oncol. 1993;20:2-12.

6. Avramis VI, Plunkett W. Metabolism and therapeutic efficacy of 9- $\beta$ D-arabinofuranosyl-2-fluoroadenine against murine leukemia P388. Cancer Res. 1982;42:2587-2591.

7. Danhauser L, Plunkett W, Keating M, et al. 9- $\beta$-D-Arabinofuranosyl2-fluoroadenine 5'-monophosphate pharmacokinetics in plasma and tumor cells of patients with relapsed leukaemia and lymphoma. Cancer Chemother Pharmacol. 1996;18:145-152.

8. Kemena A, Keating MJ, Plunkett W. Plasma and cellular bioavailability of oral fludarabine. Blood. 1991;78:52a.

9. Danhauser L, Plunkett W, Liliemark J, et al. Comparison between the plasma and intracellular pharmacology of 1-betaD-arabinofuranosylcytosine and 9-beta-D-arabinofuranosyl-2fluoroadenine 5'-monophosphate in patient with relapsed leukemia. Leukemia. 1987;1:638-643.

10. Kemena A, Gandhi V, Shewach DS, et al. Inhibition of fludarabine metabolism by arabinosylcytosine during therapy. Cancer Chemother Pharmacol. 1992;31:193-199.

11. Gandhi V, Kemena A, Keating MJ, et al. Cellular pharmacology of fludarabine triphosphate in chronic lymphocytic leukaemia cells during fludarabine therapy. Leuk Lymphoma. 1993;10:49-56. 
12. Keating MJ, O’Brien $\mathrm{S}$, Kantarjian $\mathrm{H}$, et al. Long-term follow-up of patients with chronic lymphocytic leukaemia treated with fludarabine as a single agent. Blood. 1993;81:2878-2884.

13. Keating MJ, O'Brien S, Lerner S, et al. Long-term follow-up of patients with chronic lymphocytic leukemia (CLL) receiving fludarabine regimens as initial therapy. Blood. 1998;92:1165-1171.

14. Foran JM, Oscier D, Orchard J, et al. Pharmacokinetic study of single doses of oral fludarabine phosphate in patients with 'low-grade' nonHodgkin's lymphoma and B-cell chronic lymphocytic leukemia. J Clin Oncol. 1999;17:1574-1579.

15. Oscier D, Orchard JA, Culligan D, et al. The bioavailability of oral fludarabine phosphate is unaffected by food. The Hematol $J$. 2001;2:316-321.

16. O'Rourke TJ, Burris HA, Rodriguez GI, et al. Phase I pharmacokinetic and bioavailability study of five daily intravenous and oral doses of fludarabine phosphate in patients with advanced cancer. Proc Am Soc Clin Oncol. 1997;16:210.

17. Ogawa $Y$, Hotta T, Tobinai K, et al. Phase I and pharmacokinetic study of oral fludarabine phosphate in relapsed indolent B-cell non-Hodgkin's lymphoma. Ann Oncol. 2006;17:330-333.

18. Brockman RW, Schabel Jr FM, Montgomery JA. Biological activity of 9- $\beta$-D-arabinofuranosyl-2-fluoroadenine, a metabolically stable analog of 9- $\beta$-D-arabinofuranosyladenine. Biochem Pharmacol. 1997;26:2193-2196.

19. Plunkett W, Alexander L, Chubb S, et al. Comparison of the toxicity and metabolism of $9-\beta$-D-arabinofuranosyl-2-fluoroadenine and $9-\beta-D-$ arabinofuranosyladenine in human lymphoblastoid cells. Cancer Res. 1980;40:2349-2345.

20. Plunkett W, Saunders PP. Metabolism and action of purine nucleoside analogs. Pharmacol Ther. 1991;49:2339-2368.

21. Catapano CV, Perrino FW, Fernandes DJ. Primer RNA chain termination induced by 9-beta-D-arabinofuranosyl-2-fluoroadenine 5'-triphosphate: a mechanism for DNA synthesis inhibition. $J$ Biol Chem. 1993;268:7179-7185.

22. Parker W, Cheng YC. Inhibition of DNA primase by nucleoside triphosphates and their arabinofuranosyl analogs. Mol Pharmacol. 1987;31:146-151.

23. Parker WB, Bapat AR, Shen J-X, et al. Interaction of 2-halogenated dATP analogs (F, Cl, and $\mathrm{Br}$ ) with human DNA polymerases, DNA primase and ribonucleotide reductase. Mol Pharmacol. 1988;34:485-491.

24. Tseng WC, Derse D, Cheng Y-C, et al. In vitro activity of 9- $\beta$-Darabinofuranosyl-2-fluoroadenine and the biochemical actions of its triphosphate on DNA polymerases and ribonucleotide reductase from HeLa cells. Mol Pharmacol. 1982;21:474-477.

25. White L, Shaddix SC, Brockman RW, et al. Comparison of the actions of 9- $\beta$-D-arabinofuranosyl-2-fluoroadenine and 9- $\beta$-D-arabinofuranosyladenine on target enzymes from mouse tumor cells. Cancer Res. 1982;42:2260-2264.

26. Spriggs D, Robbins G, Mitchell T, et al. Incorporation of 9- $\beta$-Darabinofuranosyl-2-fluoroadenine into HL-60 cellular RNA and DNA. Biochem Pharmacol. 1986;35:247-252.

27. Huang P, Chubb S, Plunkett W. Termination of DNA synthesis by 9$\beta$-D-arabinofuranosyl-2-fluoroadenine: a mechanism for cytotoxicity. J Biol Chem. 1990;265:16617-16625.

28. Huang P, Plunkett W. Fludarabine- and gemcitabine-induced apoptosis: incorporation of analogs into DNA is a critical event. Cancer Chemother Pharmacol. 1995a;36:181-188.

29. Huang P, Robertson LE, Wright S, et al. High molecular weight DNA fragmentation: a critical event in nucleoside analogueinduced apoptosis in leukemia cells. Clin Cancer Res. 1995b;1:1005-1013.

30. Huang P, Ballal K, Plunkett W. Biochemical characterization of the protein activity responsible for high molecular weight DNA fragmentation during drug-induced apoptosis. Cancer Res. 1997;57:3407-3414.

31. Robertson LE, Chubb S, Meyn RE, et al. Induction of apoptotic cell death in chronic lymphocytic leukemia by 2-chloro-2'-deoxyadenosine and 9-beta-D-arabinosyl-2-fluoroadenine. Blood. 1993;81:143-150.
32. Keating MJ, Kantarjian H, Talpaz M, et al. Fludarabine: a new agent with major activity against chronic lymphocytic leukemia. Blood. 1989;74:19-25.

33. Sorensen JM, Vena DA, Fallavollita A, et al. Treatment of refractory chronic lymphocytic leukemia with fludarabine phosphate via the group C protocol mechanism of the National Cancer Institute: five-year follow-up report. J Clin Oncol. 1997; 15:458-465.

34. Keating MJ, Kantarjian H, O'Brien S, et al. Fludarabine: a new agent with marked cytoreductive activity in untreated chronic lymphocytic leukemia. J Clin Oncol. 1991;9:44-49.

35. Clavio M, Miglino M, Spriano M, et al. First-line fludarabine treatment of symptomatic chronic lymphoproliferative diseases: clinical results and molecular analysis of minimal residual disease. Eur J Haematol. 1998;61:197-203.

36. Stelitano C, Morabito F, Kropp MG, et al. Fludarabine treatment in B-cell chronic lymphocytic leukaemia: response, toxicity and survival analysis in 47 cases. Haematologica. 1999;84:317-323.

37. Boogaerts MA, Van Hoof A, Catovsky D, et al. Activity of oral fludarabine phosphate in previously treated chronic lymphocytic leukemia. J Clin Oncol. 2001;19:4252-4258.

38. Rossi JF, van Hoof A, de Boeck K, et al. Efficacy and safety of oral fludarabine phosphate in previously untreated patients with chronic lymphocytic leukemia. J Clin Oncol. 2004;22:1260-1267.

39. Rai KR, Peterson BL, Appelbaum FR, et al. Fludarabine compared with chlorambucil as primary therapy for chronic lymphocytic leukaemia. N Engl J Med. 2000;343:1750-1757.

40. Johnson S, Smith AG, Löffler H, et al. Multicentre prospective randomised trial of fludarabine versus cyclophosphamide, doxorubicin, and prednisone (CAP) for treatment of advanced-stage chronic lymphocytic leukaemia. The French Cooperative Group on CLL. Lancet. 1996;347:1432-1438.

41. Leporrier M, Chevret S, Cazin B, et al. Randomized comparison of fludarabine, CAP and ChOP in 938 previously untreated stage $\mathrm{B}$ and C chronic lymphocytic leukaemia patients. Blood. 2001;98:2319-2325.

42. Spriano M, Chiurazzi F, Cassibba V, et al. Multicentric prospective randomised trial of fludarabine versus chlorambucil and prednisone in previously untreated patients with active B-chronic lymphocytic leukaemia (B-CLL): first interim report. Br J Haematol. 1998;102:191.

43. Eichhorst BF, Busch R, Obwandner T, et al. Health-related quality of life in younger patients with chronic lymphocytic leukemia treated with fludarabine plus cyclophosphamide or fludarabine alone for firstline therapy: a study by the German CLL Study Group. J Clin Oncol. 2007;25:1722-1731.

44. O'Brien S, Kantarjian H, Beran M, et al. Results of fludarabine and prednisone therapy in 264 patients with chronic lymphocytic leukemia with multivariate analysis-derived prognostic model for response to treatment. Blood. 1993;82:1695-1700.

45. Dhöner H, Fischer K, Bentz M, et al. p53 gene deletion predicts for poor survival and non-response to therapy with purine analogs in chronic B-cell leukemias. Blood. 1995;85:1580-1589.

46. Valgañón M, Giraldo P, Agirre X, et al. p53 Aberrations do not predict individual response to fludarabine in patients with B-cell chronic lymphocytic leukaemia in advanced stages Rai III/IV. Br J Haematol. 2005; 129:53-59.

47. Bellosillo B, Villamor N, Colomer D, et al. In vitro evaluation of fludarabine in combination with cyclophosphamide and/or mitoxantrone in B-cell chronic lymphocytic leukemia. Blood. 1999;94:2836-2843.

48. Koehl U, Li L, Nowak B. Fludarabine and cyclophosphamide: synergistic cytotoxicity associated with inhibition of interstrand cross-link removal. Proc Am Assoc Cancer Res. 1997;38:2.

49. Gandhi V, Nowak B, Keating MJ, et al. Modulation of arabinosylcytosine metabolism by arabinosyl-2-fluoroadenine in lymphocytes from patients with chronic ymphocytic leukemia: implications for combination therapy. Blood. 1989;74:2070-2075.

50. Seymour JF, Huang P, Plunkett W, et al. Influence of fludarabine on pharmacokinetics and pharmacodynamics of cytarabine: implications for a continuous infusion schedule. Clin Cancer Res. 1996;2:653-658. 
51. Yang L-Y, Li L, Keating MJ, et al. Plunkett W. Arabinosyl-2fluoroadenine augments cisplatin cytotoxicity and inhibits cisplatinDNA cross-link repair. Mol Pharmacol. 1995;47:1072-1079.

52. Zaffaroni N, Orlandi L, Gornati D, et al. Fludarabine as a modulator of cisplatin activity in human tumour primary cultures and established cell lines. Eur J Cancer. 1996;32A:1766-1773.

53. Knauf WU, Kreuser ED, Pottgiesser E, et al. In vitro and in vivo effectiveness of fludarabine in B-cell chronic lymphocytic leukemia (B-CLL). Ann Hematol. 1992;65:A80.

54. Elias L, Stock-Novack D, Head DR et al. A phase I trial of combination fludarabine monophosphate and chlorambucil in chronic lymphocytic leukemia: a Southwest Oncology Group study. Leukemia. 1993;7:361-365.

55. Weiss M, Spiess T, Berman E, et al. Concomitant administration of chlorambucil limits dose intensity of fludarabine in previously treated patients with chronic lymphocytic leukaemia. Leukemia. 1994;8:1290-1293.

56. Morrison VA, Rai KR, Peterson BL, et al. Impact of therapy with chlorambucil, fludarabine, or fludarabine plus chlorambucil on infections in patients with chronic lymphocytic leukemia: Intergroup Study Cancer and Leukemia Group B 9011. J Clin Oncol. 2001;19:3611-3621.

57. O'Brien S, Kantarjian HM, Cortes J, et al. Results of the fludarabine and cyclophosphamide combination regimen in chronic lymphocytic leukemia. J Clin Oncol. 2001;19:1414-1420.

58. Flinn IW, Jemiai Y, Bennett JM, et al. Fludarabine and cyclophosphamide achieves high complete response rate in patients with previously untreated chronic lymphocytic leukemia: ECOG 1997. Blood. 2000;98:633a.

59. Eichhorst BF, Busch R, Hopfinger G, et al. Fludarabine plus cyclophosphamide versus fludarabine alone in first-line therapy of younger patients with chronic lymphocytic leukaemia. Blood. 2006;107:885-891.

60. Stilgenbauer S, Eichhorst BF, Busch R, et al. Biologic and Clinical Markers for Outcome after Fludarabine (F) or F Plus Cyclophosphamide (FC) - Comprehensive Analysis of the CLL4 Trial of the GCLLSG Blood. 2008;112:2089a.

61. Flinn IW, Neuberg DS, Grever MR, et al. Phase III trial of fludarabine plus cyclophosphamide compared with fludarabine for patients with previously untreated chronic lymphocytic leukemia: US Intergroup Trial E2997. J Clin Oncol. 2007;25:793-798.

62. Catovsky D, Richards S, Matutes E, et al. Assessment of fludarabine plus cyclophosphamide for patients with chronic lymphocytic leukaemia (the LRF CLL4 Trial): a randomised controlled trial. Lancet. 2007:370:230-239.

63. Cazin B, Divine M, Leprêtre S, et al. High efficacy with five days schedule of oral fludarabine phosphate and cyclophosphamide in patients with previously untreated chronic lymphocytic leukaemia. $\mathrm{Br}$ J Haematol. 2008;143:54-59.

64. Laurenti L, Tarnani M, De Padua L, et al. Oral fludarabine and cyclophosphamide as front-line chemotherapy in patients with chronic lymphocytic leukemia. The impact of biological parameters in the response duration. Ann Hematol. 2008;87:891-898.

65. Bosch F, Ferrer A, Lopez-Guillermo A, et al. Fludarabine, cyclophosphamide and mitoxantrone in the treatment of resistant or relapsed chronic lymphocytic leukaemia. Br J Haematol. 2002;119:976-984.

66. Bosch F, Ferrer A, Villamor N, et al. Fludarabine, cyclophosphamide, and mitoxantrone as initial therapy of chronic lymphocytic leukemia: high response rate and disease eradication. Clin Cancer Res. 2008;14:155-161.

67. Mauro FR, Foa R, Meloni G, et al. Fludarabine, ara-C, novantrone and dexamethasone (FAND) in previously treated chronic lymphocytic leukemia patients. Haematologica. 2002;87:926-933.

68. Robertson LE, O'Brien S, Kantarjian H, et al. Fludarabine plus doxorubicin in previously treated chronic lymphocytic leukemia, Leukemia. 1995;9:943-945.

69. Rummel MJ, Kafer G, Pfreundschuh M, et al. Fludarabine and epirubicin in the treatment of chronic lymphocytic leukaemia: a German multicenter phase II study. Ann Oncol. 1999;10:183-188.
70. Rummel MJ, Stilgenbauer S, Gamm H, et al. Fludarabine versus fludarabine plus epirubicin in the treatment of chronic lymphocytic leukemia (CLL)-preliminary results of a randomized phase-III multicenter study. Blood. 2002;100:384a.

71. Gandhi V, Robertson LE, Keating MJ, et al. Combination of fludarabine and arabinosylcytosine for treatment of chronic lymphocytic leukemia: clinical efficacy and modulation of arabinosylcytosine pharmacology. Cancer Chemother Pharmacol. 1994;34:30-36.

72. Giles FJ, O'Brien SM, Santini V, et al. Sequential cis-platinum and fludarabine with or without arabinosyl cytosine in patients failing prior fludarabine therapy for chronic lymphocytic leukemia: a phase II study. Leuk Lymphoma. 1999;36:57-65.

73. O'Brien S, Moore JO, Boyd TE, et al. Randomized phase III trial of fludarabine plus cyclophosphamide with or without oblimersen sodium (Bcl-2 antisense) in patients with relapsed or refractory chronic lymphocytic leukaemia. J Clin Oncol. 2007;25:1114-1120.

74. Chanan-Khan A, Miller KC, Takeshita K, et al. Results of a phase 1 clinical trial of thalidomide in combination with fludarabine as initial therapy for patients with treatment-requiring chronic lymphocytic leukemia (CLL). Blood. 2005;106:3348-3352.

75. Laurenti L, Piccioni P, Tarnani M, et al. Low-dose thalidomide in combination with oral fludarabine and cyclophosphamide is ineffective in heavily pre-treated patients with chronic lymphocytic leukaemia. Leuk Res. 2007;31:253-256.

76. Huhn D, von Schilling C, Wilhelm M, et al. Rituximab therapy for patients with B-chronic lymphocytic leukemia. Blood. 2001;98:1326-1331.

77. Byrd JC, Murphy T, Howard RS, et al. Rituximab using a thrice weekly dosing schedule in B-cell chronic lymphocytic leukemia and small lymphocytic lymphoma demonstrates clinical activity and acceptable toxicity. J Clin Oncol. 2001;19:2153-2164.

78. O'Brien S, Kantarjian H, Thomas DA, et al. Rituximab dose-escalation trial in chronic lymphocytic leukaemia. J Clin Oncol. 2001;19:2165-70.

79. Byrd JC, Peterson BL, Morrison VA et al. Randomized phase 2 study of fludarabine with concurrent versus sequential treatment with rituximab in symptomatic, untreated patients with B-cell chronic lymphocytic leukemia: results from Cancer and Leukemia Group B 9712 (CALGB 9712). Blood. 2003;101:6-14.

80. Wierda W, O'Brien S, Wen S, et al. Chemoimmunotherapy with fludarabine, cyclophosphamide, and rituximab for relapsed and refractory chronic lymphocytic leukemia. J Clin Oncol. 2005;23:4070-4078.

81. Keating MJ, O'Brien S, Albitar M, et al. Early results of a chemoimmunotherapy regimen of fludarabine, cyclophosphamide, and rituximab as initial therapy for chronic lymphocytic leukemia. J Clin Oncol. 2005;23:4079-4088.

82. Byrd JC, Rai K, Peterson BL, Appelbaum FR, et al. Addition of rituximab to fludarabine may prolong progression-free survival and overall survival in patients with previously untreated chronic lymphocytic leukemia: an updated retrospective comparative analysis of CALGB 9712 and CALGB 9011. Blood. 2005;105:49-53.

83. Tam CS, O'Brien S, Wierda W, et al. Long-term results of the fludarabine, cyclophosphamide, and rituximab regimen as initial therapy of chronic lymphocytic leukemia. Blood. 2008;112:975-980.

84. Lin KI, Tam CS, Keating MJ, et al. Relevance of the immunoglobulin VH somatic mutation status in patients with chronic lymphocytic leukemia treated with fludarabine, cyclophosphamide, and rituximab (FCR) or related chemoimmunotherapy regimens. Blood. 2008;Dec 2 [Epub ahead of print].

85. Hallek M, Fingerle-Rowson G, Fink AM, et al. Immunochemotherapy with Fludarabine (F), Cyclophosphamide (C), and Rituximab (R) (FCR) Versus Fludarabine and Cyclophosphamide (FC) Improves Response Rates and Progression-Free Survival (PFS) of Previously Untreated Patients (pts) with Advanced Chronic Lymphocytic Leukemia (CLL). Blood. 2008;112:325a

86. Foon KA, Boyiadzis M, Land SR, et al. Chemoimmunotherapy with low-dose fludarabine and cyclophosphamide and high dose rituximab in previously untreated patients with chronic lymphocytic leukemia. J Clin Oncol. 2008;Dec 15 [Epub ahead of print]. 
87. Tsimberidou AM, Wierda WG, Plunkett W, et al. Phase I-II study of oxaliplatin, fludarabine, cytarabine, and rituximab combination therapy in patients with Richter's syndrome or fludarabine-refractory chronic lymphocytic leukemia. J Clin Oncol. 2008;26:196-203.

88. Bosch F, Abrisqueta P, Villamor N, et al. Rituximab, fludarabine, fyclophosphamide, and mitoxantrone (R-FCM) is a highly active chemoimmunotherapy regimen for chronic lymphocytic leukemia. Blood. 2008;112:2097a

89. Keating MJ, Flinn I, Jain V, et al. Therapeutic role of alemtuzumab (Campath-1H) in patients who have failed fludarabine: results of a large international study. Blood. 2002;99:3554-3561.

90. Hillmen P, Skotnicki AB, Robak T, et al. Alemtuzumab compared with chlorambucil as first-line therapy for chronic lymphocytic leukemia. J Clin Oncol. 2007;25:5616-5623.

91. Montillo M, Tedeschi A, Miqueleiz S, et al. Alemtuzumab as consolidation after a response to fludarabine is effective in purging residual disease in patients with chronic lymphocytic leukemia. J Clin Oncol. 2006;24:2337-2342.

92. Wendtner CM, Ritgen M, Schweighofer CD, et al. Consolidation with alemtuzumab in patients with chronic lymphocytic leukemia (CLL) in first remission - experience on safety and efficacy within a randomized multicenter phase III trial of the German CLL Study Group (GCLLSG). Leukemia. 2004;18:1093-1101.

93. Kennedy B, Rawstron A, Carter C, et al. Campath-1H and fludarabine in combination are highly active in refractory chronic lymphocytic leukemia. Blood. 2002;99:2245-2247.

94. Elter T, Borchmann P, Schulz H, et al. Fludarabine in combination with alemtuzumab is effective and feasible in patients with relapsed or refractory B-cell chronic lymphocytic leukemia: results of a phase II trial. J Clin Oncol. 2005;23:7024-7031.

95. Wierda W, Faderl S, O'Brien S, et al. Combined Cyclophosphamide, Fludarabine, Alemtuzumab, and Rituximab (CFAR) Is Active for Relapsed and Refractory Patients with CLL. Blood. 2004;104:340a.

96. Wierda W, O’Brien S, Ferrajoli A, et al. Combined Cyclophosphamide, Fludarabine, Alemtuzumab, and Rituximab (CFAR), an Active Frontline Regimen for High-Risk Patients with CLL. Blood. 2007;110:628a.

97. Montillo M, Miqueleiz S, Tedeschi A, et al. Combined Fludarabine, Cyclophosphamide, and Alemtuzumab (FCC), an Active Regimen for Treated Patients with Chronic Lymphocytic Leukemia (CLL). Blood. 2007;110:3133a.

98. Elter T, James R, Wendtner CM, et al. Treatment of patients with relapsed/refractory CLL using a combination of fludarabine, cyclophosphamide and alemtuzumab: First safety analysis of the CLL2L trial of the German CLL Study Group. J Clin Oncol. 2008;26:7053a.

99. Byrd J, Castro J, O’Brien S, et al. Comparison of results from a phase 1/2 study of lumiliximab (Anti-CD23) in combination with FCR for patients with relapsed CLL with published FCR results. Blood. 2006; 108:32a.

100. Champlin R, Khouri I, Anderlini P, et al. Nonmyeloablative preparative regimens for allogeneic hematopoietic transplantation. Bone marrow transplant. 2001;27:S13.S22.

101. Giralt S, Thall PF, Khouri I, et al. Melphalan and purine analogcontaining preparative regimens: reduced intensity conditioning for patients with hematologic malignancies undergoing allogeneic progenitor cell transplantation. Blood. 2001;97:631-637.

102. Nagler A, Slavin S, Varadi G, et al. Allogeneic peripheral blood stem cell transplantation using a fludarabine-based lowintensity conditioning regimen for malignant lymphoma. Bone Marrow Transplant. 2000;25:1021-1028.

103. Anderlini P, Giralt S, Andersson B, et al. Allogeneic stem cell transplantation with fludarabine-based, less intensive conditioning regimens as adoptive immunotherapy in advanced Hodgkin's disease. Bone Marrow Transplant. 2000;26:615-620.

104. Giralt S, Aleman A, Anagnostopoulos A, et al. Fludarabine/melphalan conditioning for allogeneic transplantation in patients with multiple myeloma. Bone Marrow Transplant. 2002;30:367-373.
105. Perez-Simon JA, Kottaridis PD, Martino R, et al. Nonmyeloablative transplantation with or without alemtuzumab: comparison between 2 prospective studies in patients with lymphoproliferative disorders. Blood. 2002;100:3121-3127.

106. Bergmann L, Fenchel K, Jahn B, et al. Immunosuppressive effects and clinical response of fludarabine in refractory chronic lymphocytic leukemia. Ann Oncol. 1993;4:371-375.

107. Anaissie EJ, Kontoyiannis DP, O'Brien S, et al. Infections in patients with chronic lymphocytic leukemia treated with fludarabine. Ann Intern Med. 1998;29:559-566.

108. Cheson BD. Infections and immunosupressive complications of purine analog therapy. J Clin Oncol. 1995; 13:2431-2448.

109. Busuttil DP, Chasty RC, Copplestone JA, et al. Infections complicating treatment of lymphoid malignancies with fludarabine. Br J Haematol. 1996;93 Suppl 1:69.

110. Cheson BD, Vena DA, Barrett J, et al. Second malignancies as a consequence of nucleoside analog therapy for chronic lymphoid leukemias. J Clin Oncol. 1999;17:2454-2460.

111. Tam CS, Seymour JF, Prince HM, et al. Treatment-related myelodysplasia following fludarabine combination chemotherapy. Haematologica. 2006;91:1546-1550.

112. Gribben JG, Zahrieh D, Stephans K, et al. Autologous and allogeneic stem cell transplantations for poor-risk chronic lymphocytic leukemia. Blood. 2005;106:4389-4396

113. Milligan DW, Fernandes S, Dasgupta R, et al. Results of the MRC pilot study show autografting for younger patients with chronic lymphocytic leukemia is safe and achieves a high percentage of molecular responses. Blood. 2005;105:397-404

114. Mauro FR, Foa R, Cerretti R et al. Autoimmune hemolytic anemia in chronic lymphocytic leukaemia: clinical, therapeutic and prognostic features. Blood. 2000;95:2786-2792.

115. Robak T, Blonski JZ, Gora-Tybor J, et al. Second malignancies and Richter's syndrome in patients with chronic lymphocytic leukemia treated with cladribine. Eur J Cancer. 2004;40:383-389.

116. Michallet M, Thiébaut A, Dreger P, et al. Peripheral blood stem cell (PBSC) mobilization and transplantation after fludarabine therapy in chronic lymphocytic leukaemia (CLL): a report of the European Blood and Marrow Transplantation (EBMT) CLL subcommittee on behalf of the EBMT Chronic Leukaemias Working Party (CLWP). $\mathrm{Br}$ J Haematol. 2000;108:595-601.

117. Morgan SJ, Seymour JF, Grigg A, et al. Predictive factors for successful stem cell mobilization in patients with indolent lymphoproliferative disorders previously treated with fludarabine. Leukemia. 2004;18:1034-1038.

118. Micallef IN, Apostolidis J, Rohatiner AZ, et al. Factors which predict unsuccessful mobilisation of peripheral blood progenitor cells following G-CSF alone in patients with non-Hodgkin's lymphoma. Hematol J. 2000;1:367-373.

119. Montillo M, Tedeschi A, Rossi V, et al. Successful CD34+ cell mobilization by intermediate-dose Ara-C in chronic lymphocytic leukemia patients treated with sequential fludarabine and Campath-1H. Leukemia. 2004;18:57-62.

120. Hallek M, Schmitt B, Wilhelm M, et al. Fludarabine plus cyclophosphamide is an efficient treatment for advanced chronic lymphocytic leukaemia (CLL): results of a phase II study of the German CLL Study Group. Br J Haematol. 2001;114:342-348.

121. Tsimberidou AM, Keating MJ, Giles FJ, et al. Fludarabine and mitoxantrone for patients with chronic lymphocytic leukemia. Cancer. 2004; 100:2583-2591.

122. Dreger P, Brand R, Hansz J, et al. Treatment-related mortality and graft-versus-leukemia activity after allogeneic stem cell transplantation for chronic lymphocytic leukemia using intensity-reduced conditioning. Leukemia. 2003;17:841-848.

123. Sorror ML, Maris MB, Sandmaier BM, et al. Hematopoietic cell transplantation after nonmyeloablative conditioning for advanced chronic lymphocytic leukemia. J Clin Oncol. 2005;23: 3819-3829. 
124. Brown JR, Kim HT, Li S, et al. Predictors of improved progression-free survival after nonmyeloablative allogeneic stem cell transplantation for advanced chronic lymphocytic leukemia. Biol Blood Marrow Transplant. 2006;12:1056-1064.

125. Delgado J, Thomson K, Russell N, et al. Results of alemtuzumab-based reduced-intensity allogeneic transplantation for chronic lymphocytic leukemia: a British Society of Blood and Marrow Transplantation Study. Blood. 2006;107:1724-1730.
126. Schetelig J, Thiede C, Bornhauser M, et al. Evidence of a graft-versusleukemia effect in chronic lymphocytic leukemia after reducedintensity conditioning and allogeneic stem-cell transplantation: the Cooperative German Transplant Study Group. J Clin Oncol. 2003;21:2747-2753. 
